OPEN ACCESS

Edited by:

Narendra Prasad Singh, University of South Carolina,

United States

Reviewed by: Udai P Singh,

University of Tennessee Health

Science Center (UTHSC),

United States

Reilly Enos,

University of South Carolina, United States

*Correspondence: Nina Chevalier nina.chevalier@uniklinik-freiburg.de

${ }^{\dagger}$ These authors have contributed equally to this work and share first authorship

Specialty section: This article was submitted to Autoimmune and Autoinflammatory Disorders, a section of the journal

Frontiers in Immunology

Received: 17 April 2021 Accepted: 23 June 2021 Published: 15 July 2021

Citation:

Schäfer A-L, Eichhorst A, Hentze C, Kraemer AN, Amend A, Sprenger DTL, Fluhr C, Finzel S, Daniel C, Salzer U, Rizzi M, Voll RE and

Chevalier N (2021) Low Dietary Fiber Intake Links Development of Obesity and Lupus Pathogenesis.

Front. Immunol. 12:696810. doi: 10.3389/fimmu.2021.696810

\section{Low Dietary Fiber Intake Links Development of Obesity and Lupus Pathogenesis}

\author{
Anna-Lena Schäfer ${ }^{1 \dagger}$, Alexandra Eichhorst ${ }^{1 \dagger}$, Carolin Hentze ${ }^{1}$, Antoine N. Kraemer ${ }^{1}$, \\ Anaïs Amend ${ }^{1}$, Dalina T. L. Sprenger ${ }^{1}$, Cara Fluhr ${ }^{1}$, Stephanie Finzel ${ }^{1}$, Christoph Daniel ${ }^{2}$, \\ Ulrich Salzer ${ }^{1}$, Marta Rizzi ${ }^{1}$, Reinhard E. Voll ${ }^{1}$ and Nina Chevalier ${ }^{1 *}$ \\ ${ }^{1}$ Department of Rheumatology and Clinical Immunology, University Medical Centre Freiburg, Freiburg, Germany, \\ 2 Department of Nephropathology, Friedrich-Alexander University (FAU) of Erlangen-Nuremberg, Erlangen, Germany
}

Changed dietary habits in Western countries such as reduced fiber intake represent an important lifestyle factor contributing to the increase in inflammatory immune-mediated diseases. The mode of action of beneficial fiber effects is not fully elucidated, but shortchain fatty acids (SCFA) and gut microbiota have been implicated. The aim of this study was to explore the impact of dietary fiber on lupus pathology and to understand underlying mechanisms. Here, we show that in lupus-prone NZB/WF1 mice low fiber intake deteriorates disease progression reflected in accelerated mortality, autoantibody production and immune dysregulation. In contrast to our original assumption, microbiota suppression by antibiotics or direct SCFA feeding did not influence the course of lupus-like disease. Mechanistically, our data rather indicate that in low fiberfed mice, an increase in white adipose tissue mass, fat-inflammation and a disrupted intestinal homeostasis go along with systemic, low-grade inflammation driving autoimmunity. The links between obesity, intestinal leakage and low-grade inflammation were confirmed in human samples, while adaptive immune activation predominantly correlated with lupus activity. We further propose that an accelerated gastro-intestinal passage along with energy dilution underlies fiber-mediated weight regulation. Thus, our data highlight the often-overlooked effects of dietary fiber on energy homeostasis and obesity prevention. Further, they provide insight into how intricately the pathologies of inflammatory immune-mediated conditions, such as obesity and autoimmunity, might be interlinked, possibly sharing common pathways.

Keywords: autoimmunity, lupus, SLE, diet, fiber, obesity, SCFA

\section{INTRODUCTION}

The significant increase of inflammatory, immune-mediated diseases in Western societies represents a global public health problem. Disorders belonging to this group include cardiovascular disease, the metabolic syndrome, allergies, cancer, and autoimmune diseases. These complex disorders are characterized by chronic inflammation in different organs usually 
associated with systemic effects. Although each disease has unique epidemiology and pathophysiology, they share the dysregulation of common inflammatory and regulatory immune pathways, central to their pathogenesis (1).

Systemic lupus erythematosus (SLE) is a prototypic autoimmune disease going along with systemic inflammation and severe organ damage, such as nephritis, hematologic or neurological complications. SLE is characterized by a loss of selftolerance, a broad dysregulation of innate and adaptive immunity and production of autoantibodies against nuclear self-antigens. Although the exact mechanisms are still unresolved, it becomes increasingly clear that the pathogenesis of SLE and other chronic inflammatory and autoimmune diseases results from a complex interplay between genetic and environmental factors. These include infectious agents, toxins as well as various lifestyle and socio-economic factors $(2,3)$.

Changed dietary habits represent one of the most influential lifestyle factors that have changed significantly over the past few decades. Generally, Westernized diets are characterized by an increased caloric intake and changed nutrient composition. Especially, intake of plant-based fiber has declined below the recommended daily dose $(4,5)$. Dietary fiber provides health benefits on different levels. Locally, an impact on composition and biodiversity of the microbiome along with an improved intestinal homeostasis and barrier function was reported $(6,7)$. For instance, populations consuming high amounts of microbiotaaccessible carbohydrates display a significant enrichment of Bacteroides. In contrast, Firmicutes enrichment and Bacteroides depletion were found in populations consuming a Westernized diet and are also associated with obesity (8-11). Further advantageous fiber effects on intestinal homeostasis and integrity comprise the promotion of mucus secretion, changed expression of tight-junction proteins and increased IgA secretion by intestinal B cells $(7,12,13)$. Moreover, dietary fiber promotes regulatory $\mathrm{T}$ cell $\left(\mathrm{T}_{\text {reg }}\right)$ expansion $(14,15)$ and IL-18 production, a cytokine important for epithelial repair (6). Systemically, fiber intake can affect diverse tissues and cells (16) and regulate energy expenditure, appetite and weight via neural and humoral pathways (17-19). Hence, in many inflammatory disorders, a fiber-rich nutrition ameliorates inflammation and delays development or progression of disease (20-25). Mechanistically, many studies highlight an important role for dietary-related metabolites controlling the different pathways. A major metabolic product of dietary fiber are short-chain fatty acids (SCFA) that derive from fermentation by commensal bacteria in the gut and modulate cell functions by epigenetic, metabolic or G-protein coupled receptor (GPCR) effects (4).

Here, we show that low compared to high fiber intake accelerates the progression of lupus and associated immunedysregulation. In contrast to our original assumption, SCFA did not play a pivotal role in mediating beneficial fiber effects. Rather, fiber intake impacted energy homeostasis preventing obesity, intestinal leakage and systemic inflammation along with slower disease progression. Hence, our findings indicate intricate actions of dietary fiber on different immune-mediated processes and disease states that may be interlinked and affect each other.

\section{MATERIALS AND METHODS}

\section{Mice and Models}

Lupus-prone NZB/WF1 mice were generated by crossing NZB/ BINJ with NZW/LacJ mice. These and MRL/MpJ-Faslpr/J were purchased from The Jackson Laboratory. For all experiments, female mice were housed on a 12-h light/dark cycle, with food and water ad libitum. To test the influence of dietary fiber, mice were fed different purified diets: a low fiber (LF) diet (Provimi Kliba diet 2122 containing $0.2 \%$ cellulose; energy content 12.9 $\mathrm{KJ} / \mathrm{g}$ ), a normal fiber (NF) diet (Provimi Kliba diet 2122 containing $4.7 \%$ cellulose; energy content $12.4 \mathrm{KJ} / \mathrm{g}$ ) and a high fiber (HF) diet (Provimi Kliba diet 2122 containing $4.7 \%$ cellulose and $15 \%$ pectin (Herbstreith \& Fox); energy content $11.4 \mathrm{KJ} / \mathrm{g}$ ). All diets were purchased from Kliba Nafag. Provimi Kliba diet 2122 is composed of the following major nutrients: 93.9\% dry matter, $18 \%$ crude protein, $5 \%$ crude fat, $0.3 \%$ crude fiber, $3.5 \%$ crude ash, $67.1 \%$ NFE and $42.5 \%$ starch). To test the influence of SCFA, mice were fed standard chow (Provimi Kliba diet 3807.PX.L10), and a mix of $100 \mathrm{mM} \mathrm{Na}$-Acetate, $50 \mathrm{mM} \mathrm{Na}$ Propionate and $50 \mathrm{mM}$ Na-Butyrate (Sigma-Aldrich) was supplemented in the drinking water. For gut microbiota suppression, mice were administered a broad-spectrum antibiotic mix of neomycin (1 g/L, Fisher Scientific) and vancomycin $(0.5 \mathrm{~g} / \mathrm{L}, \mathrm{Hikma})$. All treatments were started after weaning at roughly 4 weeks of age and continued throughout the entire duration of the experiment. To test systemic effects of inflammatory cytokines, mice were injected three times per week and over a period of 6 weeks ( $20 \mathrm{w}-26 \mathrm{w}$ of age) with a mix of recombinant TNF $\alpha$, IL-6 and IL-1 $\beta$ (100 ng each) or PBS (vehicle). Blood and urine were collected and mice were euthanized at defined time points for organ harvest and downstream experiments. In survival studies, mice were regularly monitored and euthanized when reaching defined ethical endpoints (proteinuria plus deteriorating general health condition and/or significant weight loss). To determine gross food intake, three to five non-nephritic mice of equal age and treatment group were group-housed. On three following days, $24 \mathrm{~h}$ food intake was determined as the difference in weight between the food put into that cage and that remaining at the end of $24 \mathrm{~h}$. The mean of the three measurements was calculated and divided by the number of co-housed animals to determine the average intake per mouse over $24 \mathrm{~h}$.

\section{Human Subjects}

Supplementary Tables 3, 4 give a summary on patients and healthy controls included into the study, their sex, median age (years), SLEDAI, BMI $\left(\mathrm{kg} / \mathrm{m}^{2}\right)$, serum levels of leptin $(\mathrm{pg} / \mathrm{ml})$, CRP ( $\mathrm{mg} / \mathrm{l})$, and endotoxemia $(\mathrm{pg} / \mathrm{ml})$, and a summary on current treatment, including steroids (prednisone).

\section{Assessment of Proteinuria}

Urine samples were collected by spontaneous urination or in metabolic cages (Tecniplast). For a semi-quantitative measurement of proteinuria, Albustix test strips (Siemens) were used. According to the color scale provided by the manufacturer, 
albuminuria was categorized as follows: $0-1=$ trace, $1=30,2=$ $100,3=300$ and $4>2,000 \mathrm{mg} / \mathrm{dl}$.

\section{Assessment of Anti-dsDNA Autoantibodies and IgG Subclasses}

IgG, IgG2a and IgG1 antibody secretion directed against dsDNA was determined by enzyme-linked immunosorbent assay (ELISA). Briefly, 384-well microtiter plates (Greiner Bio One) were pre-coated with $20 \mu \mathrm{g} / \mathrm{ml}$ Poly-L-Lysin (Sigma-Aldrich) for $1 \mathrm{~h}$ at $37^{\circ} \mathrm{C}$ followed by coating with $20 \mu \mathrm{g} / \mathrm{ml}$ calf thymus DNA (Sigma-Aldrich) at $4^{\circ} \mathrm{C}$ o.n. Plates were blocked with $2 \%$ fetal calf serum (FCS) in PBS for $2 \mathrm{~h}$ at RT. Samples were diluted in 2\% FCS in PBS and incubated for $2 \mathrm{~h}$ at RT. Bound anti-dsDNA immunoglobulins were detected with HRP-conjugated secondary antibodies specific for mouse IgG, IgG1 or IgG2a (SouthernBiotech), followed by development with TMB substrate (Thermo Fisher Scientific) according to the manufacturer's protocol. The absorbance at $450 \mathrm{~nm}$ was measured using the Spark ${ }^{\circledR} 10 \mathrm{M}$ multimode microplate reader (Tecan). To determine autoantibody titers, expressed as arbitrary unit (A.U.), reference sera were used to create a standard curve.

\section{Flow Cytometry Mouse Samples}

Single cell suspensions of spleen and kidney were obtained by mechanic dissociation [in some experiments by enzymatic digestion using collagenase (5 $\mathrm{mg} / \mathrm{ml}$, Life Technologies)]. Following incubation with anti-CD16/32 antibodies (101330, BioLegend) to block non-specific Fc receptor binding, single cell suspensions were stained with biotin- or fluorochromeconjugated monoclonal antibodies diluted in 2\% FCS/PBS for 30 min on ice. For intracellular or intranuclear staining, cells were fixed and permeabilized with BD Cytofix/Cytoperm ( $B D$ Biosciences) or eBioscience FoxP3/Transcription Factor Staining Buffer Set (eBioscience), respectively. For intracellular cytokine staining, cells were re-stimulated with $50 \mathrm{ng} / \mathrm{ml}$ PMA (SigmaAldrich), $1 \mu \mathrm{g} / \mathrm{ml}$ Ionomycin (Sigma-Aldrich) and Brefeldin A (eBioscience) for $4 \mathrm{~h}$ at $37^{\circ} \mathrm{C} / 5 \% \mathrm{CO}_{2}$ prior staining and fixation. The following antibodies were used: Annexin V APC (640941, BioLegend), TCR $\beta$ chain Biotin (109203, BioLegend), CD19 Biotin (115505, BioLegend), NK1.1 Biotin (108704, BioLegend), Ly6G Biotin (127604, BioLegend), CXCR5 Biotin (551960, BD Biosciences), $\kappa$ light chain Biotin (559750, BD Biosciences), $\lambda$ light chain Biotin (553433, BD Biosciences), CD11c APC (170111482, eBioscience), CD11b FITC (101205, BioLegend), Ly6G V450 (560603, BD Biosciences), Ly6C PE-Cy7 (560593, BD Biosciences), CD45 APC-Cy7 (103115, BioLegend), PDCA1 PE (1231782, eBioscience), Streptavidin-PerCP-Cy5.5 (45431782, BD Biosciences), CD45R/B220 Pacific Blue (103230, BioLegend), CD11c PE-Cy7 (117318, BioLegend), CD80 APC-Fire750 (104738, BioLegend), CD86 APC (7086281, eBioscience), TCR $\beta$ chain APC-Cy7 (109219, BioLegend), CD4 PE-Cy7 (100422, BioLegend), CD8a PerCP (100732, BioLegend), PD-1 PE (1299858, eBioscience), Streptavidin-APC (17431782, eBioscience), CD44 FITC (103021, BD Biosciences), CD45 eFluor506 (69045182, eBioscience), IFN $\gamma$ APC (505809,
BioLegend), IL-10 FITC (505005, BioLegend), IL-17 PE (559302, BD Biosciences), FoxP3 APC (17577382, eBioscience), CD103 PE (557495, BD Biosciences), CD138 PE (5537, BD Biosciences), CD45R/B220 APC-Cy7 (103224, BioLegend), Streptavidin-V450 (560797, BD Biosciences), GL7 FITC (553666, BD Biosciences), Fas PE (554258, BD Biosciences), TCR $\beta$ chain PerCP (109227, BioLegend), CD21 FITC (553818, BD Biosciences), and CD23 PE (553139, BD Biosciences). The following immune cell subsets were identified (Supplementary Figures 5, 6): B cells (\% TCR $\beta^{-} \mathrm{B} 220^{+} /$ live or $\mathrm{CD}_{4} 5^{+}$cells), germinal center B cells ( $\%$ Fas ${ }^{\text {hi }} \mathrm{GL}^{\mathrm{hi}} / \mathrm{B}$ cells), plasma cells/blasts (\% CD $138^{\text {hi }} \mathrm{LC}^{+} /$live cells), marginal zone $\mathrm{B}$ cells (\% CD $21^{\mathrm{hi}} \mathrm{CD} 23^{\mathrm{lo}} / \mathrm{B}$ cells), follicular $\mathrm{B}$ cells (\% CD $21^{1 \mathrm{lo}} \mathrm{CD} 23^{\mathrm{hi}} / \mathrm{B}$ cells), $\mathrm{CD} 4^{+}$and $\mathrm{CD} 8^{+} \mathrm{T}$ cells $\left(\% \mathrm{TCR} \beta^{+} \mathrm{B} 220^{-} \mathrm{CD} 4^{-} \mathrm{CD} 8^{+}\right.$or $\mathrm{TCR}^{+} \mathrm{B} 220^{-} \mathrm{CD} 8^{-} \mathrm{CD} 4^{+} /$live or $\mathrm{CD} 45^{+}$cells), expression of IFN $\gamma, \mathrm{IL}-17, \mathrm{IL}-10$ and $\mathrm{CD} 44^{\text {hi }}$ on $\mathrm{CD}^{+}$or $\mathrm{CD}^{+} \mathrm{T}$ cells, regulatory $\mathrm{T}$ cells $\left(\mathrm{T}_{\text {reg }}\right)\left(\% \mathrm{FoxP}^{+} / \mathrm{CD} 4^{+} \mathrm{T}\right.$ cells), effector $\mathrm{T}_{\text {reg }}\left(\% \mathrm{CD}_{103}{ }^{+} / \mathrm{T}_{\text {reg }}\right)$, follicular $\mathrm{T}$ helper cells $\left(\mathrm{T}_{\mathrm{FH}}\right)$ (\% CXCR $5^{\text {hi }} \mathrm{PD}-1^{\text {hi }} / \mathrm{CD} 4^{+} \mathrm{T}$ cells), $\mathrm{cDC}$ and $\mathrm{pDC}\left(\mathrm{CD} 11 \mathrm{c}^{\mathrm{hi}}\right.$ or

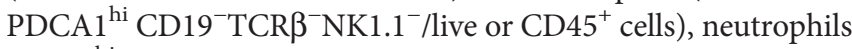
(Ly6G ${ }^{\text {hi }} \mathrm{CD} 11 \mathrm{~b}^{+} \mathrm{CD} 19^{-} \mathrm{TCR} \beta^{-} \mathrm{NK} 1.1^{-} /$live or $\mathrm{CD} 45^{+}$cells),

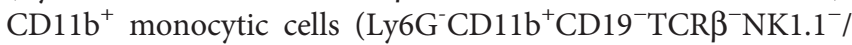
live or $\mathrm{CD} 45^{+}$cells) and expression of CD80 or CD86 on monocytic cells and cDC. In kidney, additionally CD45 staining was included. To identify apoptotic cells, Annexin V staining was performed using Annexin V Binding Buffer (BD Biosciences).

\section{Human Samples}

Whole EDTA-blood was stained with fluorochrome-conjugated monoclonal antibodies followed by red blood cell lysis using OptiLysis B (Beckman Coulter) according to manufacturer's protocol. The following antibodies were used: CD3 BV421 (562436, BD Biosciences), CD4 PE-Cy7 (348809, BD Biosciences), CD8 PerCP (344707, BioLegend), HLA-DR FITC (347400, BD Biosciences). Determined were: expression of the activation marker HLA-DR on whole $\mathrm{CD}^{+}, \mathrm{CD}^{+} \mathrm{CD}^{+}$or $\mathrm{CD}^{+} \mathrm{CD}^{+}$ T cells.

Flow cytometric analysis was performed at BD LSR Fortessa flow cytometer (Becton Dickinson) followed by data analysis using FlowJo ${ }^{\mathrm{TM}}$ Software (Becton Dickinson).

\section{Real-Time Quantitative PCR}

Total RNA was extracted using TRIzol reagent (Invitrogen), and the QuantiTect Reverse Transcription Kit (Qiagen) was used for cDNA synthesis according to the manufacturer's instructions. Transcripts were quantified by real-time quantitative PCR on a StepOnePlus $^{\mathrm{TM}}$ Real-Time PCR System (Applied Biosystems) with predesigned TaqMan Gene Expression Assays and reagents according to manufacturer's instructions (Applied Biosystems). Probes with the following Applied Biosystems assay identification numbers were used: Mm99999915_g1 (GAPDH), Mm00434226_m1 (IL-18), Mm00434228_m1 (IL1ß), Mm00446190_m1 (IL-6), Mm00434759_m1 (Leptin), Mm01276696_m1 (Muc2), Mm00441127_m1 (Reg3), Mm00443258_m1 $(T N F \alpha)$ and Mm00500912_m1 (ZO-1). For each sample, $m R N A$ abundance was normalized to the amount of GAPDH and is presented in arbitrary units (A.U.). 


\section{Assessment of Intestinal Integrity by FITC Dextran Assay}

To measure intestinal leakage, FITC-Dextran (Sigma-Aldrich) was administered via oral gavage ( $600 \mathrm{mg} / \mathrm{kg}$ body weight). After $4 \mathrm{~h}$, mice were sacrificed and blood was collected for serum preparation. Fluorescence intensity (excitation $485 \mathrm{~nm}$, emission $535 \mathrm{~nm}$ ) was measured in 96-well black flat-bottom plates (Corning ${ }^{\mathrm{TM}}$ Costar $^{\mathrm{TM}}$, Thermo Fisher Scientific) at the Spark ${ }^{\circledR}$ $10 \mathrm{M}$ multimode microplate reader (Tecan).

\section{Assessment of Endotoxemia by LPS Measurement}

Serum LPS levels were measured using HEK-Blue LPS Detection assay (Invivogen). HEK-Blue ${ }^{\text {TM }}$ hTLR4 cells were cultured in DMEM high glucose medium (Gibco) supplemented with GlutaMAX (Gibco), 1\% Penicillin/Streptomycin (Gibco) and HEK-Blue Selection (Invivogen) at $37^{\circ} \mathrm{C}$ in humidified air supplemented with $5 \% \mathrm{CO}_{2}$. To measure LPS in serum samples, $2.5 \times 10^{4}$ cells were incubated for $24 \mathrm{~h}$ in the presence of $20 \mu \mathrm{l}$ cell culture medium plus $80 \mu \mathrm{l}$ serum. Secreted embryonic alkaline phosphatase (SEAP) activity in supernatant was then measured by incubating $180 \mu \mathrm{l}$ QUANTI Blue Solution with $20 \mu \mathrm{l}$ cell culture supernatant for $90 \mathrm{~min}$ at $37^{\circ} \mathrm{C}$. OD at $620 \mathrm{~nm}$ was measured at the Infinite F50 microplate reader (Tecan). A negative control (culture medium) was included as well as supernatants of cells incubated with different LPS concentrations (E. coli O55:B5, Sigma-Aldrich) to calculate a standard curve.

\section{Assessment of Cytokine and Leptin Levels by Plex Assays}

Cytokine levels in mouse serum were determined using the LEGENDplex Mouse Inflammation Panel (BioLegend), human leptin levels in serum using a customized LEGENDplex Panel (BioLegend) and mouse leptin using a customized Bio-Plex assay (Bio-Rad). The assays were performed according to the manufactures instructions, LEGENDplex assays were analyzed at BD LSRFortessa flow cytometer (Becton Dickinson), Bio-Plex assays at Luminex LX200 (Bio-Rad).

\section{Statistics}

For statistical analysis Instat software Prism (GraphPad software) was used. $P$-values less than or equal to 0.05 were considered significant. Statistical comparison between two, or more than two experimental groups were performed using Mann-Whitney U-test and Kruskal-Wallis-test, respectively. The Kaplan-Meier method was used for estimating and displaying OS rates. Outliers were determined by ROUT method. To analyze the association between different parameters Spearman's rank correlation coefficients were calculated.

\section{Study approval \\ Animal}

Animal experiments were approved by the local governmental commission for animal protection of Freiburg (Regierungspräsidium Freiburg, approval nos. G16/58 and G19/21).

\section{Human}

Experiments were conducted according to the principles expressed in the Declaration of Helsinki as Ethics Statement. The study was in accordance with the ethical standards set by the institutional ethics committee (RB approval numbers 210/20 and $624 / 14)$. All participants gave their informed consent prior to the inclusion in the study.

\section{RESULTS}

\section{Low Intake of Dietary Fiber Deteriorates Disease Progression in Lupus-Prone NZB/WF1 Animals}

To explore the effects of fiber intake on lupus pathogenesis, lupus-prone NZB/WF1 mice were continuously fed a high (HF), normal (NF) and low fiber (LF) diet. In addition to poorly fermentable cellulose, the soluble fiber pectin was supplemented in HF diet as this had resulted in markedly diverse gut microbial communities and high intestinal SCFA levels in previous studies (25). Considering an average intake of 8,370 KJ per day, the consumption of a HF, LF or NF diet would correspond to an intake of 144, 1.29 or $31.75 \mathrm{~g}$ fiber per day, respectively. Hence, the fiber content of the NF diet corresponds roughly to the recommended daily fiber intake of human adults, while HF and LF diet are at the upper and lower end as in many other studies. Generally, LF-treated mice showed accelerated disease progression compared to HF-treated mice, reflected in significantly reduced overall survival (OS) (Figure 1A). Compared to NF-fed mice, OS also appeared to be reduced, however this was not statistically significant. Overall and in accordance with that, we detected highest serum levels of antidsDNA-IgG in the LF-cohort. Serum levels of anti-dsDNAIgG2a, an IgG subclass known to mediate pro-inflammatory effector function (26), were found to be significantly increased in the LF- compared to the HF-group (Figure 1B). Compared to NF-treated mice, anti-dsDNA-IgG2a levels were only slightly and not significantly increased, as observed for OS. No differences were found for anti-dsDNA-IgG1, while whole antidsDNA-IgG was slightly, although not significantly increased in LF- compared to HF-treated mice (Figure 1B). Given these mild, dose-dependent effects of dietary fiber on lupus progression, all further experiments to clarify the underlying pathology were performed with HF- versus LF-treatment only. More advanced lupus-like disease in LF-treated animals was further reflected in a significantly higher lymphoid hyperplasia/splenomegaly (Figure 1D), but only slightly increased proteinuria and frequencies of kidney-infiltrating leukocytes, indicative of renal injury (Figures 1C, E). Likewise, LF-feeding reduced OS in lupus-prone MRL/lpr mice, while no significant anti-dsDNAIgG titer differences were found (Supplementary Figure 1).

Altogether, these results indicate overall detrimental effects of low fiber intake on lupus pathogenesis. Nutritional intake of high compared to normal fiber amounts did only yield slight additional benefits. 


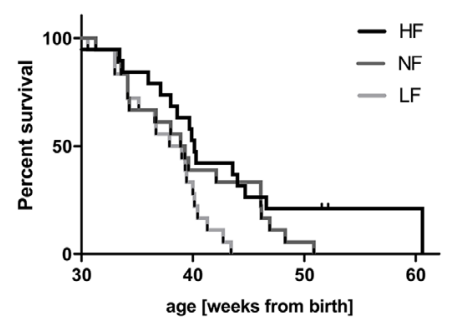

C

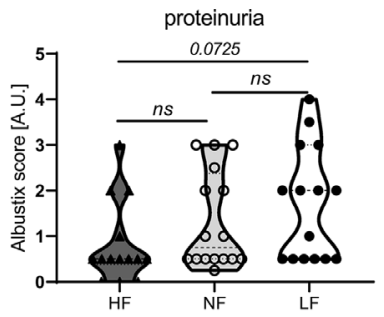

HFvs. NF: $n$ S HFvs. LF: $0.0099 \quad$ NFvs. LF: 0.0782

B

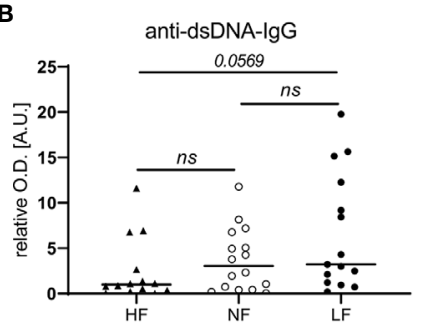

D

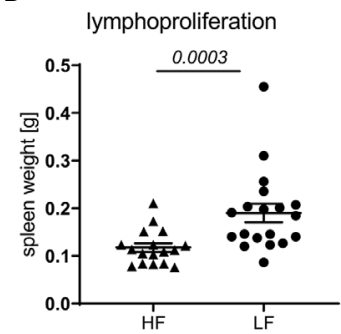

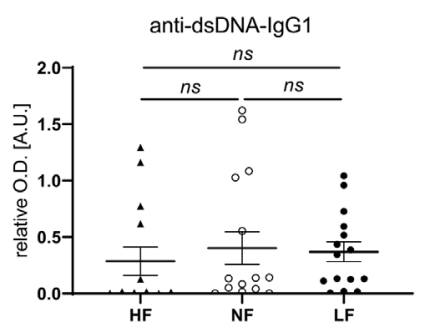

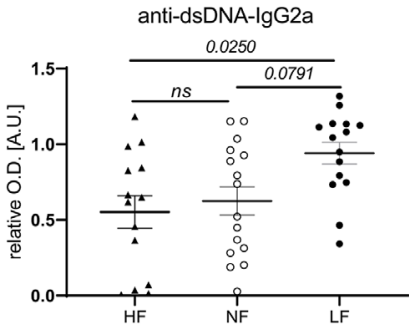

E

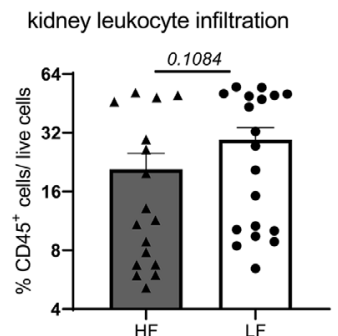

FIGURE 1 | Low intake of dietary fiber accelerates disease in lupus-prone NZBNF1 mice. (A) Overall survival (OS) determined in lupus-prone NZBMF1 mice fed a high (HF; $n=19)$, normal (NF; $n=18$ ) or low fiber ( $L F ; n=18$ ) diet. The Kaplan-Meier method was used for estimating OS in differently treated groups. (B-D) Determination of (B) total anti-dsDNA-lgG, -lgG1 and -lgG2a serum titers, (D) lymphoproliferation by spleen weight, (C, E) signs of beginning nephritis by kidney-infiltrating CD45 leukocytes and proteinuria levels, in 28 w old animals fed a HF ( $n=14-17$ mice), NF ( $n=16$ mice) or LF ( $n=15-19$ mice) diet. Results are expressed as scatter blots with mean \pm SEM; each data point represents an individual mouse; $p<0.05$ was considered significant, $p>0.2$ is indicated as $n s$, not significant.

\section{Low Intake of Dietary Fiber Accelerates the Adoption of an Inflamed Immune Phenotype}

Dietary fiber and SCFA are known to have broad effects on innate and adaptive immunity (16) going along with changed disease pathologies. To clarify such a connection in our model we examined systemic changes in distribution, activation and differentiation of major immune cell populations in spleen and kidney of 12-14 w old, yet healthy NZB/WF1 mice, in $28 \mathrm{w}$ old animals with established autoantibodies but no signs of overt nephritis (proteinuria $\leq 30 \mathrm{mg} / \mathrm{dl}$ ) and such with signs of advanced disease (proteinuria $\geq 300 \mathrm{mg} / \mathrm{dl}$ ) (Figure 2 and Supplementary Table 1).

Expectedly, we noted a significant increase in lymphoproliferation and total cell counts as well as immune phenotypical changes in healthy compared to diseased animals (Supplementary Figure 2A; Supplementary Table 2). With respect to the distribution of main immune cell populations, most pronounced was the relative decrease of $\mathrm{CD}^{+}$and to a lesser degree $\mathrm{CD}^{+} \mathrm{T}$ cells in spleen and their concomitant accumulation in kidneys. We were not able to clarify the reason underlying these frequency shifts. Spleen T cells in nephritic compared to healthy NZB/WF1 animals did neither show an increased susceptibility to apoptosis, nor was there a more pronounced migration of $\mathrm{T}$ cells towards inflamed versus noninflamed kidneys (Supplementary Figure 3) under the employed conditions. Further possible explanations could be an enhanced T cell proliferation in inflamed organs as well as a lower replenishment of the peripheral cell pool by the cytopenic bone marrow (data not shown) of diseased animals. In contrast to kidneys, we found a relative increase of splenic neutrophils and classical dendritic cells (cDC), while plasmacytoid dendritic cells (pDC) dropped in both organs. While expression of co-stimulatory CD80 and CD86 on cDC

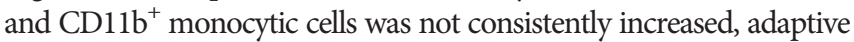
immune cells adopted an 'inflamed phenotype' with progressing disease. In both, kidney and spleen, this comprised a significantly higher expression of the activation marker CD44 and cytokine IFN $\gamma$ on T cells, while IL-17 was barely expressed, an enhanced $\mathrm{T}_{\mathrm{FH}}$ differentiation along with increased $\mathrm{B}$ cell differentiation in plasma and germinal center (GC) B cells and a concomitant decrease in marginal zone (MZ) and follicular B cells. Strong co-expression of 
A
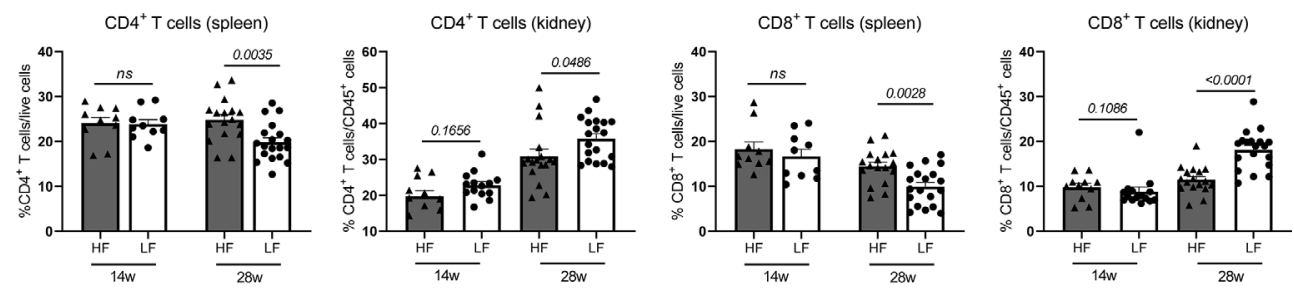

B
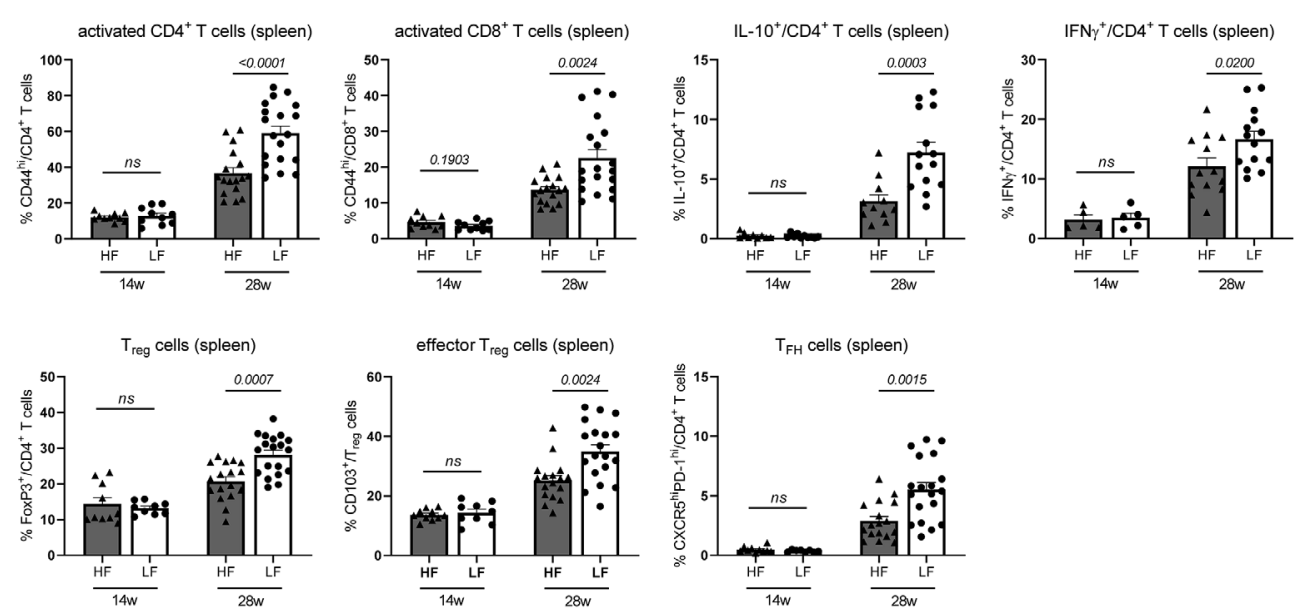

C
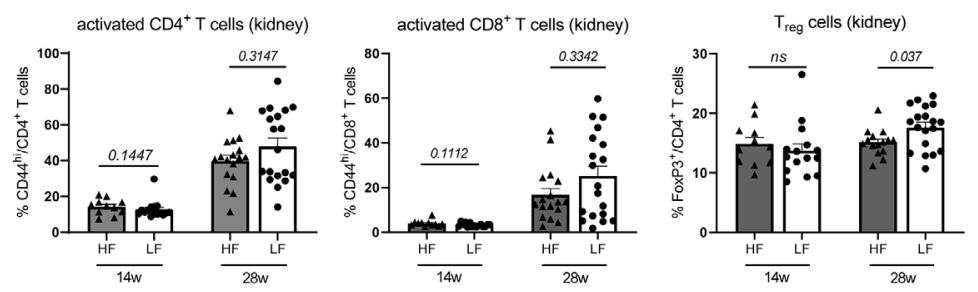

D
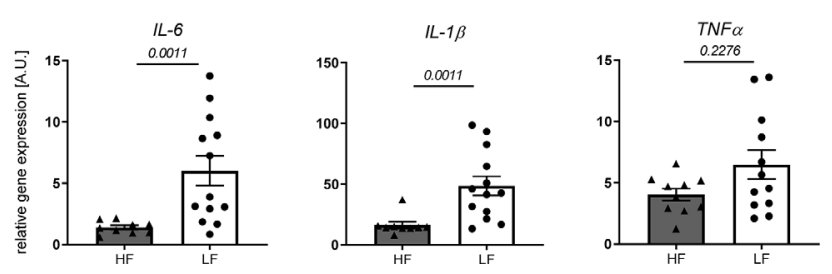

FIGURE 2 | HF-treated mice display a less inflamed immune status. (A-C) Broad immune status evaluation in HF- and LF-treated NZBNF1 mice by FACS in 14 w ( $\mathrm{n} \mathrm{HF/LF}=10-15$ mice) and $28 \mathrm{w}$ old animals ( $\mathrm{HF}=11-17$ mice, $\mathrm{n} \mathrm{LF}=14-19$ mice). (A) Relative proportions of $\mathrm{CD} 4^{+}$and CD8 ${ }^{+} \mathrm{T}$ cells in spleen and kidney. (B, C) Most prominent differences in immune cell differentiation between HF- and LF-treated mice: CD44 ${ }^{\text {hi }}$ expression on CD4 ${ }^{+}$and $C D 8^{+}$as marker of T cell activation, expression of IL-10 or IFN $\gamma$ on CD4 $4^{+} T$ cells, frequencies of FoxP3 ${ }^{+} T_{\text {reg }}$, CD103 ${ }^{+} F o x P 3^{+}$effector $T_{\text {reg }}$ and $C X C R 5^{\text {hi } P D-~}{ }^{\text {hi }} T_{F H}$ cells. (D) Relative $m R N A$ expression of IL-6, IL-1 $\beta$ and TNF $\alpha$ was examined in kidneys of $28 \mathrm{w}$ old animals ( $\mathrm{n} \mathrm{HF}=9-10$ mice, $\mathrm{n} \mathrm{LF}=12-13$ mice). Results are expressed as scatter blots with mean \pm SEM; each data point represents an individual mouse; $p<0.05$ was considered significant, $p>0.2$ is indicated as $n s$, not significant.

CD44 and IFN $\gamma$ in CD4 and CD8 T cells (Supplementary Figure 4) might point out that activated $\mathrm{T}$ cells also represent main mediators of important effector functions. $\mathrm{CD} 4^{+} \mathrm{T}$ cells of diseased animals also displayed elevated levels of anti-inflammatory IL-10, and greater frequencies of regulatory $\mathrm{T}$ cells $\left(\mathrm{T}_{\text {reg }}\right)$ and $\mathrm{CD}_{103}{ }^{+}$effector $\mathrm{T}_{\text {reg }}$ in kidney and spleen, which we interpret as counter-regulatory antiinflammatory immune response in the setting of active disease.
Consistent with that, an increase of $\mathrm{T}_{\text {regs }}$ and IL-10 is reported in lupus-prone mice and patients with disease progression (27).

In accordance with the slower disease progression and less pronounced lymphoproliferation in $28 \mathrm{w}$ old HF- compared to LF-treated mice we not only found reduced splenocyte counts (Supplementary Figure 2B), but also immune changes that more closely resembled that of yet healthy animals, 
predominantly within the $\mathrm{T}$ cell compartment (Supplementary Table 1 and Figure 2). Here, we noted not only significant differences in $\mathrm{CD}^{+}$and $\mathrm{CD} 8^{+}$frequency shifts in spleen and kidney (Figure 2A and Supplementary Table 1), but also an increased expression of CD44, IFN $\gamma$ and IL-10 on CD $4^{+} \mathrm{T}$ cells and higher frequencies of $\mathrm{T}_{\text {reg, }}$, effector $\mathrm{T}_{\text {reg }}$ and $\mathrm{T}_{\mathrm{FH}}$ cells in LFmice (Figure 2B and Supplementary Table 1). In parts, these patterns of a more inflamed immune phenotype were also found in kidney $\mathrm{CD}^{+}$(increase in IFN $\gamma^{+}$and FoxP3 ${ }^{+} \mathrm{T}_{\text {reg }}$ ) and spleen $\mathrm{CD}^{+} \mathrm{T}$ cells (CD44 ${ }^{\text {hi }}$ expression), as well as in innate immune cells (CD80 and CD86 expression on cDC, relative drop in spleen

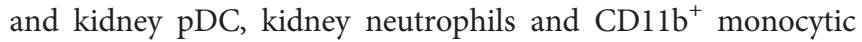
cells) (Figures 2B, C and Supplementary Table 1). Supporting these observations, partly similar differences in spleen $\mathrm{T}$ cells and innate immune cells were also noted for nephritic HF- versus LFtreated animals, while only sporadic differences were found in the inflamed kidney. Kidneys of $28 \mathrm{w}$ old LF-treated mice also displayed a significantly increased expression of inflammatory $I L-1 \beta$ and $I L-6 m R N A$ (Figure 2D). No pioneering differences were noted in $14 \mathrm{w}$ old, yet healthy animals (Supplementary Figures 2B, C; Supplementary Table 1).

To summarize, the more favorable disease course in HFcompared to LF-treated animals was also reflected in immunologic changes. Given, that these appeared at large and only at later disease stages, may argue against the notion that dietary fiber skews the differentiation of specific immune cells; it does however not exclude such a scenario. Our results may rather point out that low fiber intake accelerates immune-dysregulation and in concert with that disease progression.

\section{Intake of Dietary Fiber Impacts Weight Development, Intestinal Homeostasis, and Adipose Tissue and Systemic Inflammation Affecting Disease Pathology}

Fiber intake can influence disease and immune responses in different ways. Given reported associations between fiber consumption, weight regulation, intestinal homeostasis and autoimmune pathology $(28,29)$ we explored such a connection in our study. We noted that HF-fed mice continuously presented a lower body weight with the exception of the first weeks after weaning (Figure 3A). This was paralleled by a clearly decreased mass of gonadal white adipose tissue (WAT) (Figure 3B). Largely increased feces production combined with significantly higher daily chow consumption and energy intake suggest that an accelerated gastro-intestinal passage along with energy dilution may underlie the lower weight gain in these mice (Figure 3C). Significantly increased colon and small intestine lengths further support these assumptions (Figure 3D). These may result from the hygroscopic pectin effects increasing fecal volume and viscosity, posing a higher mechanical strain and stretch on the intestinal wall and stronger propulsive peristalsis $(29,30)$. Consequently, fiber intake also affected intestinal homeostasis. In FITC-dextran permeability assays, HF-treated animals showed improved intestinal integrity (Figure 3E) and a significant transcriptional upregulation of Mucin-2, known to be involved in mucus layer formation and protection of the intestinal wall from self-digestion and microbial contact (31) (Figure 3F). We also found a slight, but not significant transcriptional upregulation of molecules associated with antimicrobial defense $(\operatorname{Reg} 3 b)$ as well as epithelial repair (IL-18), while the gut barrier molecule ZO-1 was not differently expressed (Figure 3F). While IL-6 was equally expressed between LF and HF animals, IL-1 $\beta$ and TNF $\alpha$ showed a significant and slight increase in the colon of LF mice, respectively (Figure 3F). In addition to the increased intestinal leakage, this might point towards a slightly enhanced intestinal inflammation.

Obesity and intestinal dysbiosis are not only interlinked, but also important drivers of chronic inflammation (32-38). In accordance with that and apart from a mere increase in WAT mass (Figure 3B) and leptin transcripts (Figure 4A), LF-treated animals displayed signs of exacerbated fat inflammation as shown by significantly increased inflammatory $I L-1 \beta$ and $T N F \alpha$, and slightly increased IL-6 $m R N A$ expression (Figure 4A). A subset of inflammatory markers was found to be elevated systemically as well. In LF-mice, we found increased leptin serum concentrations along with significantly higher levels of GM-CSF, TNF $\alpha$, IL- 6 and MCP1 while IFN $\gamma$, IL-23, IL-10 and IL-17 showed only a slight, not significant increase (Figure 4B).

To examine if typical pro-inflammatory cytokines might affect adaptive immune activation and link chronic inflammation to disease pathology, we treated $20 \mathrm{w}$ old NZB/ WF1 animals over a period of 6 weeks with a mix of recombinant TNF $\alpha$, IL- 6 and IL-1 $\beta$. Compared to PBS-treated control animals, continuous cytokine application significantly increased lymphoproliferation and CD44 expression on CD8, but not CD4 T cells. We also noted a more pronounced, although not significantly increased production of anti-dsDNA-IgG (Figure 4C). While these results largely support our assumptions, they do not allow a clear distinction between adaptive immune activation being directly triggered by inflammatory cytokines versus developing along with more quickly progressing disease.

Altogether, our results indicate that fiber intake impacts intestinal integrity, energy homeostasis and weight regulation. These may synergistically propagate a state of chronic, systemic, low-grade inflammation, tipping the balance towards an accelerated autoimmune pathology along with a proinflammatory immune-phenotype.

\section{Human Obesity Is Associated With Intestinal Leakage and Systemic Inflammation While Adaptive Immune Activation Shows a Predominant Correlation With SLE Activity}

To strengthen the assumption of the linkage of obesity with intestinal leakage, systemic inflammation and adaptive immune activation as potential drivers of disease pathology, we further examined this connection in SLE patients.

Compared to healthy controls (HC) and according to our observations in NZB/WF1 mice (Supplementary Figure 2A; Supplementary Table 2), SLE patients displayed significantly 
A

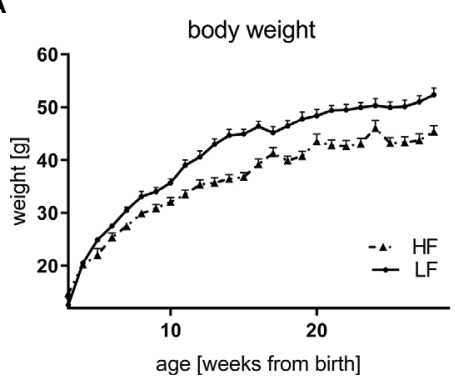

C

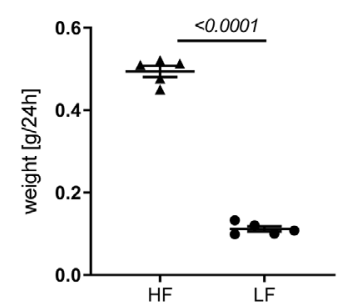

body weight

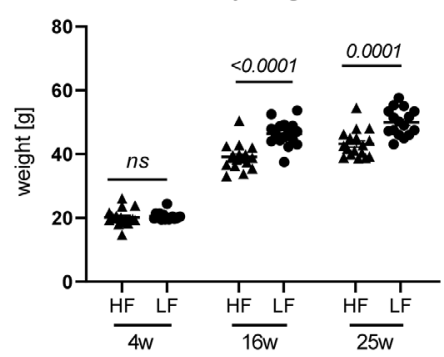

food intake

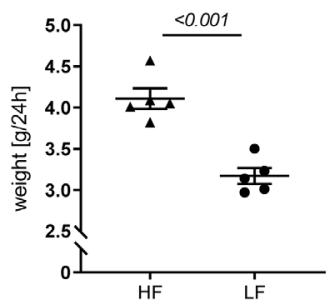

B
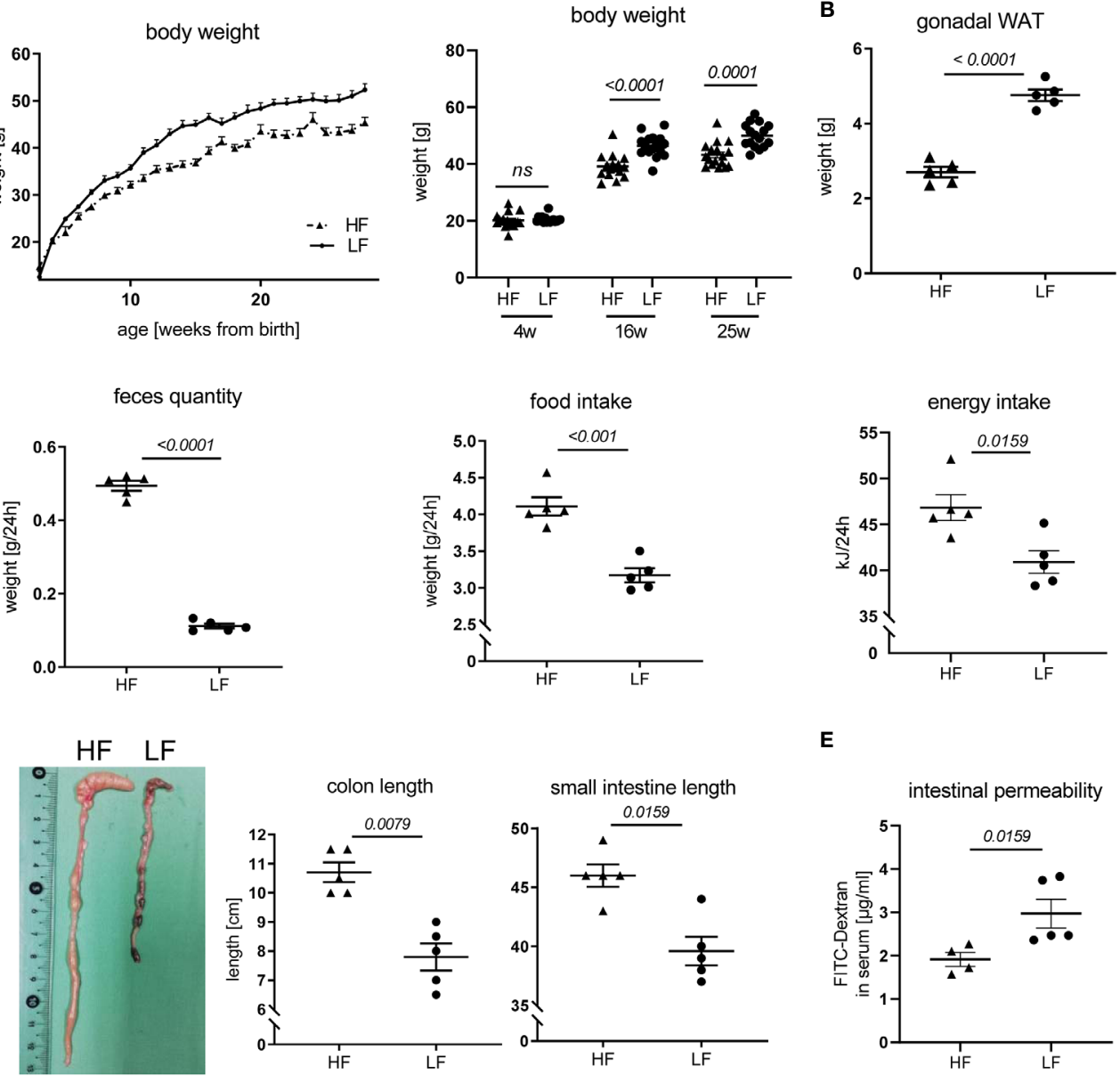

$\mathbf{F}$
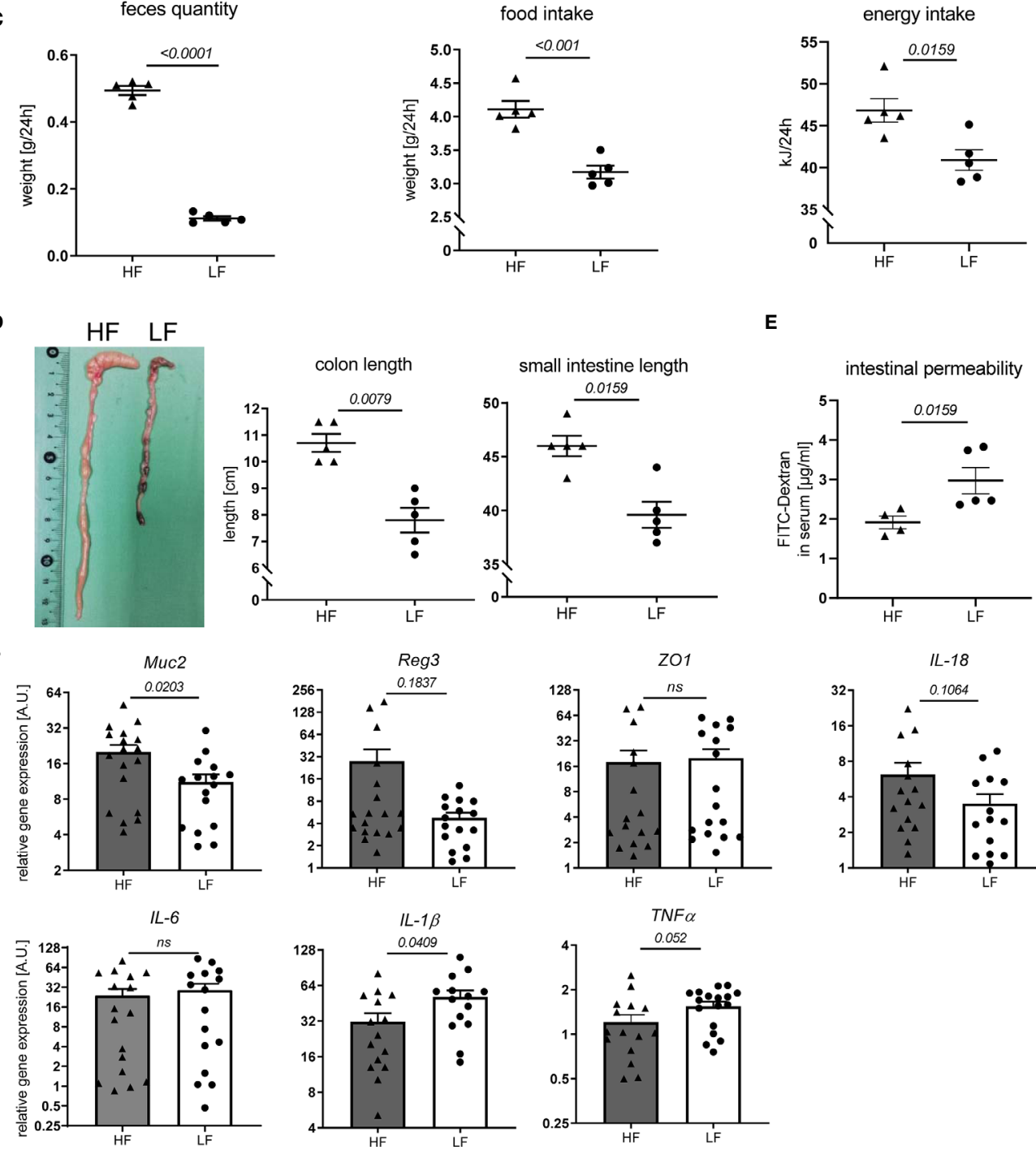

E
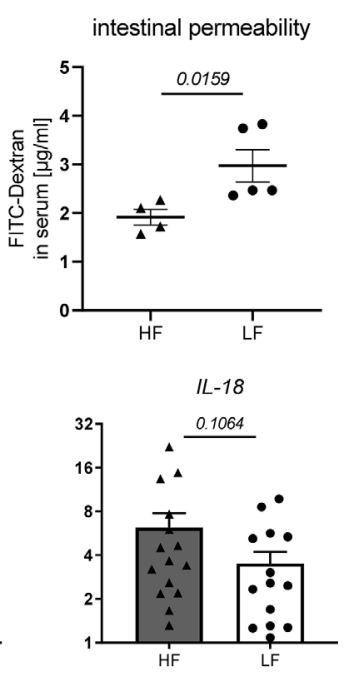

FIGURE 3 | Impact of dietary fiber on weight regulation and intestinal homeostasis. Lupus-prone NZBMF1 mice were fed a HF- or LF-diet. (A) Body weights are shown from 3-28 weeks of age (left) and at defined time points (right) ( $\mathrm{HF}=18$ mice, $n \mathrm{LF}=16$ mice; representative of two independent experiments).

(B-D) Weight of gonadal white adipose tissue (WAT) (B), feces quantity, food and energy intake per day (C) as well as lengths of small intestine and colon

(D) were determined at $28 \mathrm{w}$ ( $\mathrm{n} \mathrm{HF/LF}=5$ mice, representative of at least two independent experiments). (E) Quantification of intestinal permeability with FITC-

Dextran applied by oral gavage in $28 \mathrm{w}$ old animals $(\mathrm{n} \mathrm{HF}=4$ mice, $\mathrm{n} \mathrm{LF}=5$ mice, representative for two independent experiments). (F) Relative $m R N A$ expression of molecules associated with gut barrier function and inflammation in colon of $28 \mathrm{w}$ old animals ( $\mathrm{n} \mathrm{HF}=15-18$ mice, $\mathrm{n} \mathrm{LF}=15-17$ mice). Results are expressed as scatter blots or trend line with mean \pm SEM; each data point represents an individual mouse; $p<0.05$ was considered significant, $p>0.2$ is indicated as $n s$, not significant. 
A
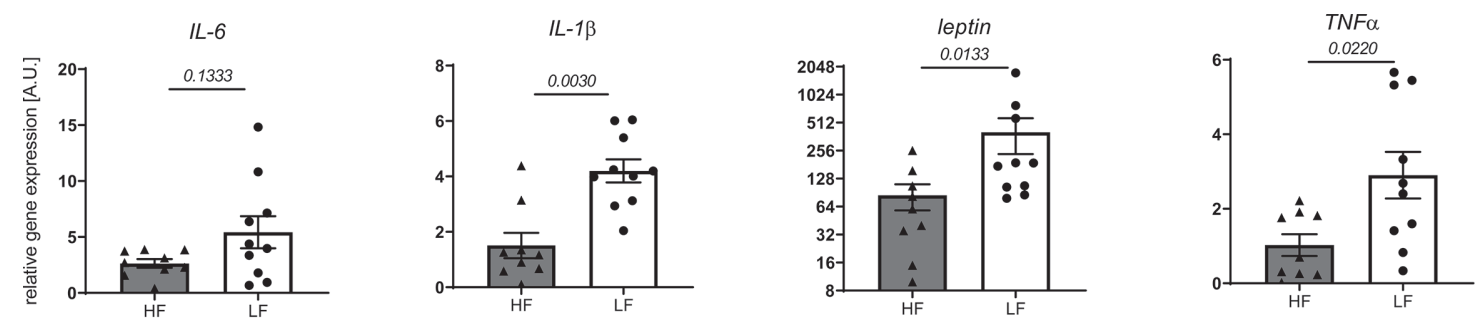

B
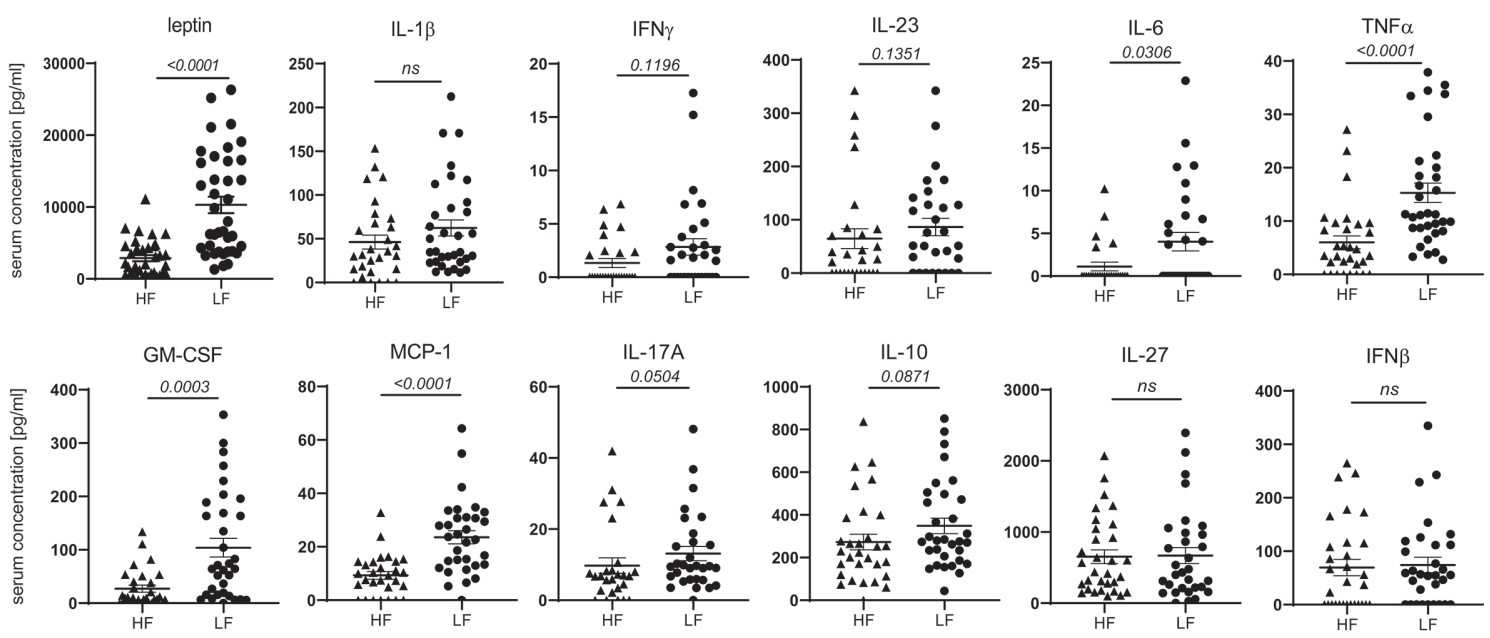

C
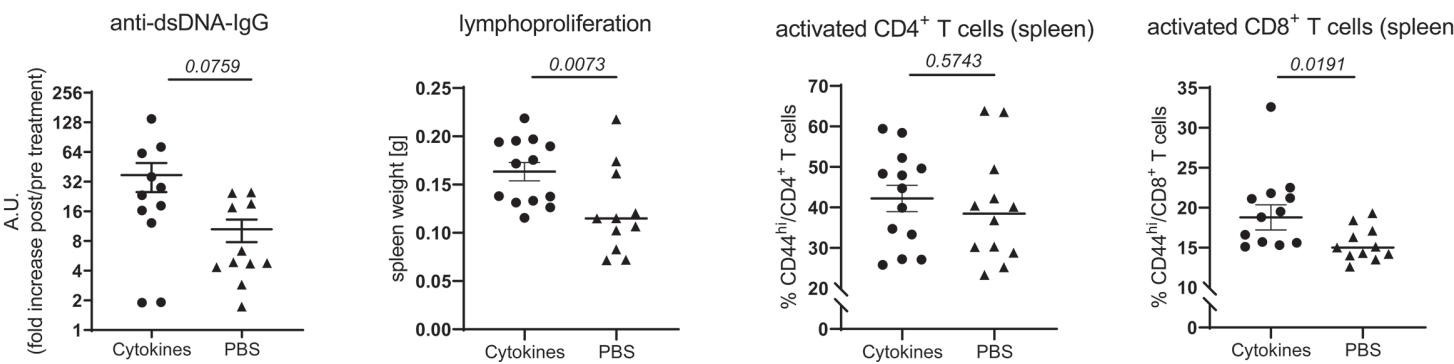

FIGURE 4 | Link between dietary fiber, WAT and systemic inflammation and lupus pathology. Lupus-prone NZBNF1 mice were fed a HF- or LF-diet. (A) Relative mRNA expression of IL-1 $\beta, I L-6, T N F \alpha$ and leptin was examined in gonadal WAT of $28 \mathrm{w}$ old animals ( $\mathrm{H} \mathrm{HF}=9$ mice, $\mathrm{n} L F=10$ mice). (B) Serum concentrations of leptin and a panel of cytokines in $28 \mathrm{w}$ old animals were determined by Plex assays ( $\mathrm{HF}=26-35$ mice, $n$ LF $=30-38$ mice). (C) $20 \mathrm{w}$ old NZB/WF1 mice were treated over a period of 6 weeks with a mix of recombinant TNF $\alpha$, IL- 6 and IL-1 $\beta$ or PBS; determined was the increase in anti-dsDNA-IgG post- compared to pre-treatment as well as development of lymphoproliferation (spleen weight) and expression of $\mathrm{CD} 44$ on $\mathrm{CD} 4^{+}$and $\mathrm{CD} 8^{+} \mathrm{T}$ cells post-treatment $(\mathrm{n}$ cytokines $=11-$ 13 ; $\mathrm{n}$ PBS $=11-12)$. Results are expressed as scatter blots with mean $\pm \mathrm{SEM}$; each data point represents an individual mouse; $p<0.05$ was considered significant, $p>0.2$ is indicated as $n s$, not significant.

increased immune activation, determined by expression of HLA$\mathrm{DR}$ on $\mathrm{CD}^{+} \mathrm{CD}^{+}, \mathrm{CD}^{+} \mathrm{CD}^{+}$and whole $\mathrm{CD}^{+} \mathrm{T}$ cells (Figures 5A, B). In SLE patients, the level of immune activation of $\mathrm{CD}^{+}$and whole $\mathrm{T}$ cells clearly, of $\mathrm{CD}^{+} \mathrm{T}$ cells slightly correlated with disease activity, determined by SLEDAI (Figure 5C and Table 1).

To explore a possible association of disease activity with systemic inflammation, obesity and intestinal leakage, we determined serum levels of the acute phase reactant C-reactive protein (CRP), serum lipopolysaccharide (LPS) as indirect measure of intestinal leakage as well as body mass index (BMI) and leptin serum levels as measure of obesity. In contrast to the positive association between SLEDAI and immune activation, we did not find a correlation between disease activity (SLEDAI) and CRP or LPS levels and even a negative correlation with BMI and leptin (Figure 5C and Table 1). These results might be explained by a) CRP in general not being a typical SLE activity marker; b) the confounding effects of different therapeutic regimes with usually highest corticosteroid doses on top of treatment with biologicals and DMARDs in patients with elevated disease 
A
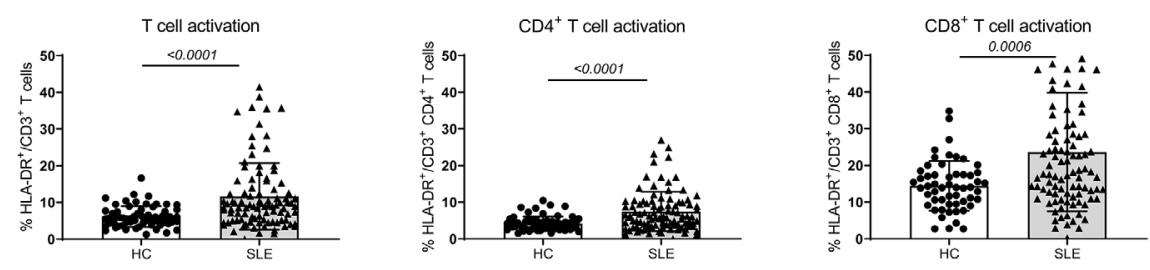

B

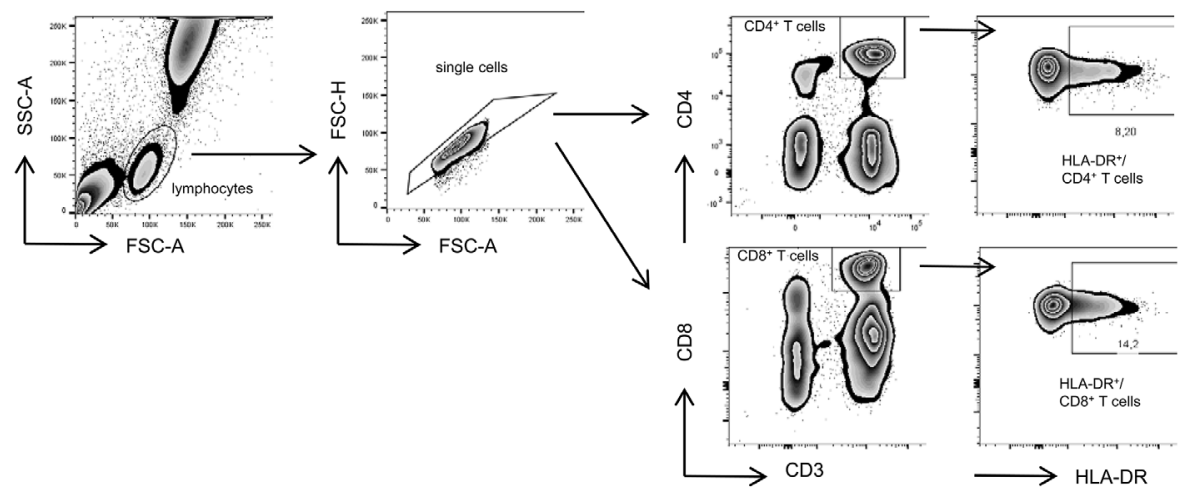

C
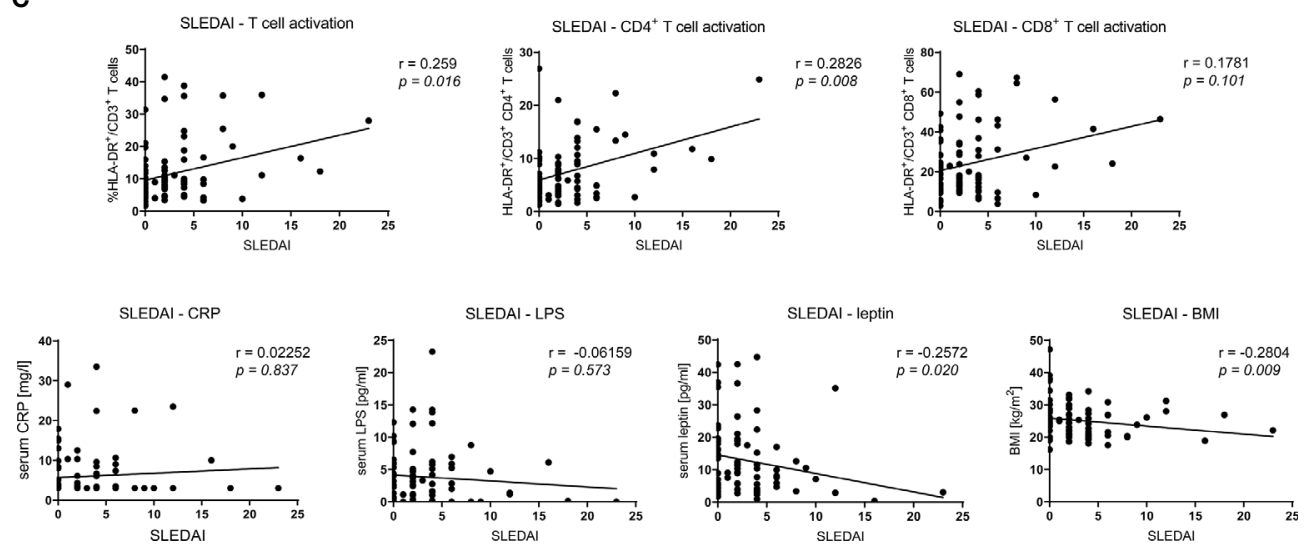

FIGURE 5 | Association between SLE activity, obesity, intestinal leakage, inflammation and adaptive immune activation. (A) Comparison of HLA-DR expression as marker of immune activation on $\mathrm{CD}^{+}, \mathrm{CD}^{+} \mathrm{CD}^{+}$and $\mathrm{CD}^{+} \mathrm{CD}^{+} \mathrm{T}$ cells in SLE patients $(\mathrm{n}=86)$ and healthy controls $(\mathrm{HC} ; \mathrm{n}=67)$. Results are expressed as scatter blots with mean \pm SEM; each data point represents an individual donor; $p<0.05$ was considered significant. (B) Representative FACS-blots indicating the selection of lymphocytes, doublet-exclusion, selection of $\mathrm{CD} 3^{+} \mathrm{CD} 4^{+}$or $\mathrm{CD} 3^{+} \mathrm{CD} 8^{+} \mathrm{T}$ cells and expression analysis of HLA-DR. (C) The relationship between disease activity (SLEDAl) and obesity (BMI and serum leptin), systemic inflammation (CRP), gut leakage (serum LPS) as well as adaptive immune activation (\% HLA-DR expression on $\mathrm{CD}^{+}, \mathrm{CD}^{+} \mathrm{CD}^{+}$and $\mathrm{CD}^{+} \mathrm{CD}^{+} \mathrm{T}$ cells) was analyzed by Spearman's rank correlation; graphed are numerical values, Spearman's rank correlation coefficient and its strength.

activity, which is also found in our study (Supplementary Table 4); c) weight loss being a frequent clinical sign of active disease (B symptoms).

Therefore, we decided to examine these associations also in healthy controls (HC) and in a more defined group of lowly active SLE patients ('SLE subgroup') with a SLEDAI $\leq 2$, receiving a treatment of not more than hydroxychloroquine/chloroquine and/or prednisone $\leq 5 \mathrm{mg}$ and no immunosuppressants or biologicals. Generally, for all SLE patients, HC and the 'SLE subgroup' we observed a positive and mostly significant correlation of obesity (BMI) with leptin and CRP, in HC and the 'SLE subgroup' additionally between BMI and LPS levels (Table 1). Generally, the observed correlations were strongest for
$\mathrm{HC}$, possibly due to the fact, that there are no or less confounding effects from disease, co-morbidities or medication.

In contrast to the overall association between obesity, intestinal leakage and low-grade inflammation, we did not find a clear correlation between obesity and markers of immune activation (Table 1). Only within the subgroup of SLE patients, the BMI correlated positively with immune activation in $\mathrm{CD} 8^{+} \mathrm{T}$ cells, while there was no such correlation for $\mathrm{CD}^{+}$and whole $\mathrm{CD}^{+}$ $\mathrm{T}$ cells. No correlation and rather a slightly negative association was found between BMI and immune activation in the group of all enrolled SLE patients and HC (Table 1). With regard to the overall weak or lacking correlation between BMI and immune activation, it needs to be considered, that: a) immune activation shows a clear 
TABLE 1 | Association between SLE activity, obesity, intestinal leakage, systemic inflammation and adaptive immune activation.

\begin{tabular}{|c|c|c|c|c|c|}
\hline & & \multirow{2}{*}{$\begin{array}{c}\begin{array}{c}\text { SLEDAl } \\
\text { Correlation }^{A}\end{array} \\
\text { SLE }\end{array}$} & \multicolumn{3}{|c|}{$\begin{array}{c}\text { BMI } \\
\text { Correlation }^{\text {B }}\end{array}$} \\
\hline & & & $\mathrm{HC}$ & SLE & SLE sub \\
\hline \multirow[t]{2}{*}{ BMl } & r & -0.2804 & & & \\
\hline & $p$ & 0.009 & & & \\
\hline \multirow[t]{2}{*}{ leptin } & $r$ & -0.2572 & 0.7529 & 0.5876 & 0.7143 \\
\hline & $p$ & 0.02 & $<0.001$ & $<0.001$ & $<0.001$ \\
\hline \multirow[t]{2}{*}{ CRP } & $r$ & 0.02252 & 0.5874 & 0.2257 & 0.3402 \\
\hline & $p$ & 0.837 & $<0.001$ & 0.038 & 0.071 \\
\hline \multirow[t]{2}{*}{ LPS } & $r$ & -0.06159 & 0.4437 & 0.105 & 0.386 \\
\hline & $p$ & 0.573 & $<0.001$ & 0.339 & 0.039 \\
\hline \multirow[t]{2}{*}{$\% H L A-D R / \mathrm{CD}^{+} \mathrm{T}$ cells } & $r$ & 0.259 & -0.07666 & -0.05047 & 0.197 \\
\hline & $p$ & 0.016 & 0.547 & 0.646 & 0.306 \\
\hline \multirow[t]{2}{*}{$\% \mathrm{HLA}-\mathrm{DR} / \mathrm{CD}^{+}{ }^{+} \mathrm{CD} 4^{+} \mathrm{T}$ cells } & r & 0.2826 & -0.007213 & -0.007213 & 0.05172 \\
\hline & $p$ & 0.008 & 0.955 & 0.136 & 0.79 \\
\hline \multirow[t]{2}{*}{$\% \mathrm{HLA}-\mathrm{DR} / \mathrm{CD}^{+} \mathrm{CD}^{+} \mathrm{T}$ cells } & $r$ & 0.1781 & -0.05827 & -0.1629 & 0.3542 \\
\hline & $p$ & 0.101 & 0.647 & 0.136 & 0.059 \\
\hline
\end{tabular}

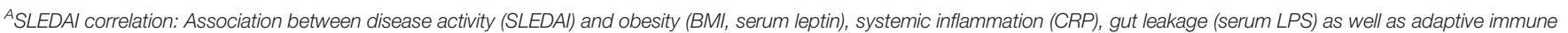
activation (\% HLA-DR expression on $C D 3^{+}, C D 3^{+} C D 4^{+}$and $C D 3^{+} C D 8^{+} T$ cells) in all enrolled SLE patients $(n=86)$.

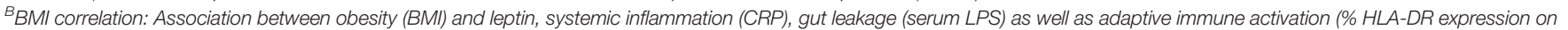

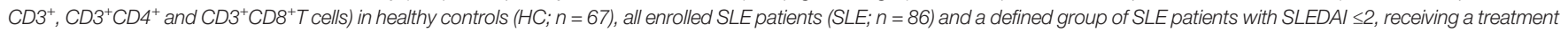
of no more than hydroxychloroquine/chloroquine, prednisone $\leq 5 \mathrm{mg}$ and no DMARDs/biologicals (SLE sub; $n=29$ ).

${ }^{A}, B$ Graphed are numerical values, Spearman's rank correlation coefficient and its strength.

association with SLE activity/SLEDAI; consequently, immune activation is generally low in HC and the lowly active 'SLE subgroup'. b) The lack of correlation in all SLE patients is likely explained by the negative correlation between disease activity and $\mathrm{BMI}$, with weight loss being a frequent clinical sign of active disease (B symptoms) (Figures 5A, C and Table 1).

Altogether, these results partly support our murine data. They strengthen the hypothesis of an association of obesity with intestinal leakage and systemic inflammation. That clear signs of elevated adaptive immune activation were predominantly found in SLE patients with active disease, points out the requirement of stimuli such as antigen exposure. Although a clear association between obesity and immune activation could not be established, it cannot be excluded, that in the setting of SLE, factors like obesity might additionally push adaptive immune activation and sustain disease activity. A further limitation is that in this human cohort, we were not able to explore the link between fiber intake and obesity, reported in mice.

\section{Neither Gut Microbiota Suppression, nor SCFA Feeding Exert Predominant Effects on Disease Pathogenesis in NZB/WF1 Mice}

As SCFA and bacterial metabolism are influenced by dietary fiber intake and can affect inflammatory diseases on various levels, we also set out to explore to what extent their actions might influence disease pathology in our model. To that end, NZB/ WF1 mice were continuously fed a mix of the most abundant SCFA (Acetate, Butyrate and Propionate). To assess the role of gut microbiota, we suppressed bacterial growth by application of broad spectrum antibiotics. Antibiotics treatment affected neither OS, nor autoantibody production or weight regulation (Figure 6A). In addition, we did not find clearly beneficial effects when feeding SCFA. Overall, SCFA feeding hardly improved OS, while it decreased spleen weights. No differences were found for proteinuria as well as anti-dsDNA-IgG levels (Figure 6B). Apart from an increase in $\mathrm{T}_{\text {reg }}$ and effector $\mathrm{T}_{\text {reg }}$ frequencies, no immune-phenotypical changes were observed upon SCFA treatment (Supplementary Table 5 and Figure 6D). Like in HF-fed mice, but less pronounced, SCFA-treated animals presented lower body weights, however there were no differences in intestinal leakage (Figure 6C).

Altogether, these results suggest that SCFA-feeding does not exert significantly beneficial effects on lupus pathology in our model. In support of that, also systemic SCFA application (data not shown) or maternal SCFA feeding during pregnancy and lactation (data not shown) had no effects.

\section{DISCUSSION}

The central question of this study was to elucidate whether a lack of fiber, as typically found in Western type diets, contributes to lupus pathogenesis and to unravel underlying mechanisms. We hypothesized that bacterial metabolism and especially the generation of SCFA might play a leading role by fortifying a healthy intestinal homeostasis and beneficial immunologic effects. This hypothesis was supported in some aspects by our results, as low intake of dietary fiber accelerated lupus pathology and the associated immune-dysregulation. Surprisingly, direct SCFA feeding did not influence lupus manifestation. Our data indicate that rather an increase in WAT mass and fatinflammation link reduced fiber intake and lupus pathogenesis in our model. We hypothesize that this, combined with intestinal leakiness, inflicts a state of systemic low-grade inflammation accelerating disease development. These data not only add to the understanding how low fiber intake may propagate autoimmune pathogenesis, but also how intricately the pathologies of 
A
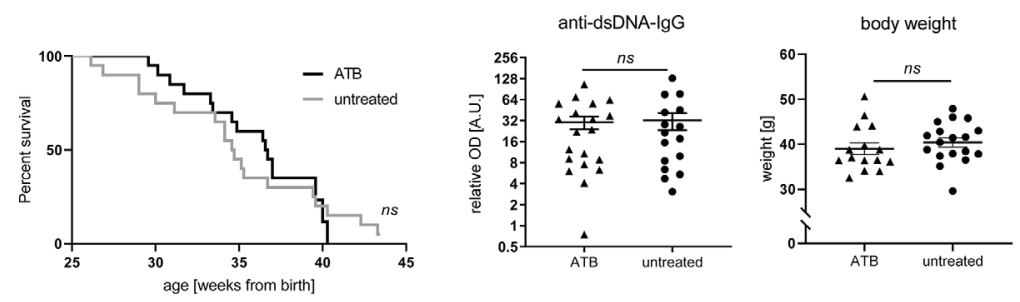

B
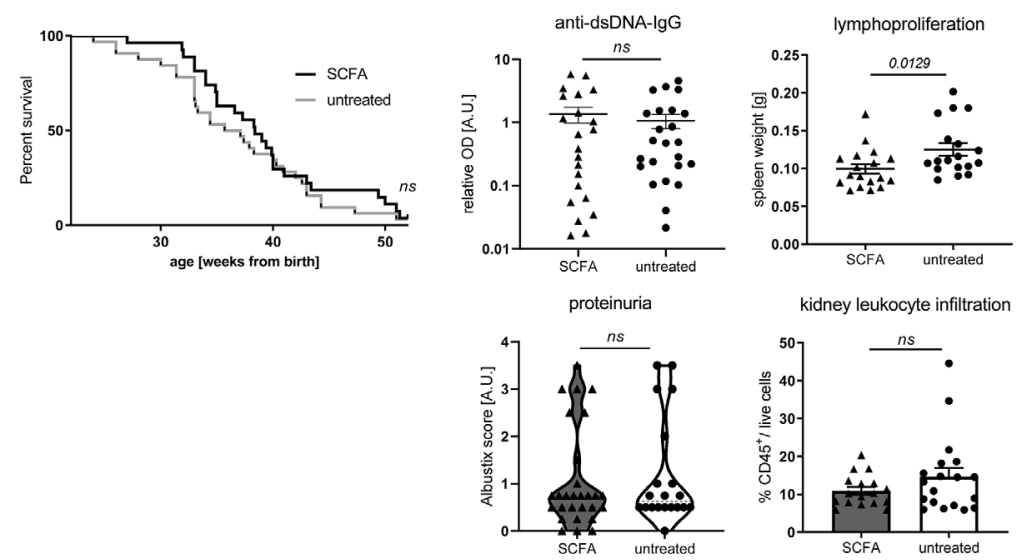

C
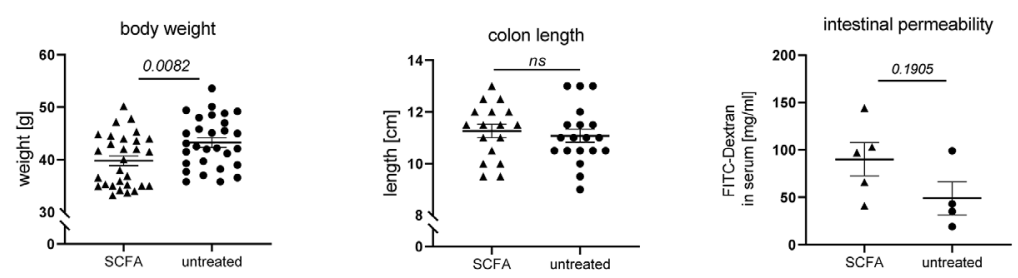

D
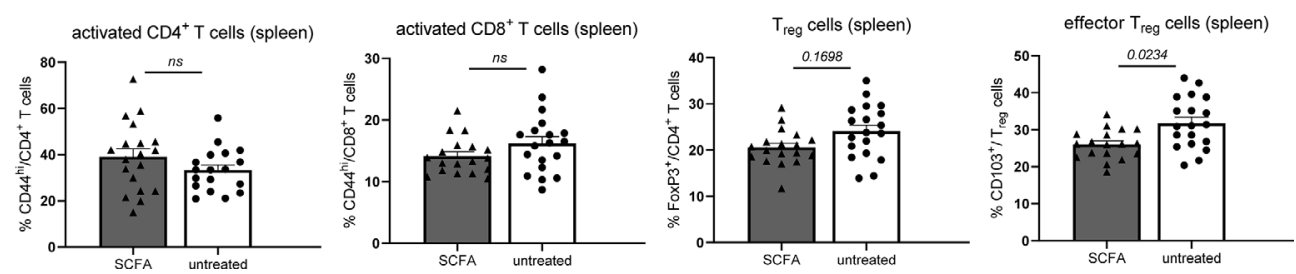

FIGURE 6 | Impact of SCFA application or microbiota suppression on disease development in NZB/WF1 animals. (A) Lupus-prone NZBMF1 mice were administered antibiotics (ATB) in the drinking water $(n=15-20$ mice) versus untreated drinking water $(n=18-20$ mice). Overall survival as well as anti-dsDNA autoantibodies and body weight were determined at $28 \mathrm{w}$. (B-D) Lupus-prone NZB/WF1 mice received a SCFA-mix or untreated drinking water. (B) Overall survival ( $\mathrm{S}$ SCFA $=27$ mice, $\mathrm{n}$ untreated $=32$ mice), anti-dsDNA autoantibodies, proteinuria and kidney infiltration by leukocytes, as well as spleen weights as sign of lymphoproliferation were determined at $28 \mathrm{w}$ ( $\mathrm{n}$ SCFA $=17-22$ mice, $\mathrm{n}$ untreated $=18-24$ mice). (C) Body weight ( $\mathrm{n}$ SCFA=26-29 mice, $\mathrm{n}$ untreated $=29$ mice), colon length ( $\mathrm{n}$ SCFA $=18$ mice, $n$ untreated $=19$ mice) as well as intestinal permeability with FITC-Dextran applied by oral gavage, were determined at $28 \mathrm{w}$ ( $\mathrm{n}$ SCFA $=5$ mice, $n$ untreated $=4$ mice; representative of two independent experiments). (D) Broad immune status evaluation in spleen of $28 \mathrm{w}$ old NZB/WF1 mice receiving a SCFA-mix $(n=18)$ or untreated drinking water $(n=19)$. Depicted are CD44 ${ }^{\text {hi }}$ expression on $C D 4^{+}$and $C D 8^{+}$as marker of T cell activation as well as

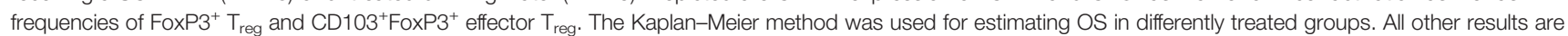
expressed as scatter blots with mean \pm SEM; each data point represents an individual mouse; $p<0.05$ was considered significant, $p>0.2$ is indicated as ns, not significant.

inflammatory immune mediated conditions, such as autoimmunity and obesity, are interlinked.

Generally, our study supports most published work in this area propagating an association between fiber intake and the pathogenesis of different immune-mediated inflammatory diseases such as allergic, autoimmune and cancerous conditions (20-25) and parameters of metabolic syndrome (39-41). In particular, our data support the connection between low fiber intake, obesity and intestinal leakage as drivers of inflammation and lupus pathology. 
The here prevailing inverse association between fiber consumption and reduced body fat/obesity is supported by other studies (42). Generally, a myriad of different fiber effects might contribute, such as a changed microbiota (43-45), enhanced satiety and lower food intake, an accelerated gastro-intestinal transit along with increased energy absorption (42, 46-49), as well as changed SCFA contents influencing energy expenditure, appetite and weight via neural and humoral pathways (17-19). The lacking effect of antibiotics treatment argues against microbiota shifts playing a major role in weight development in our model. We hypothesize a major contribution by reduced energy exploitation in HF-fed mice as a consequence of an accelerated intestinal passage along with increased fecal bulking and laxation and enlarged intestinal lengths. The latter most probably results from the hygroscopic fiber effects increasing fecal volume and viscosity, posing a higher mechanical strain and stretch on the intestinal wall and stronger propulsive peristalsis (42, 47-49). Although not directly shown, increased food and energy intake by HF-fed animals further supports the postulated energy loss and argues against a connection between fiber intake and enhanced satiety as alternative anti-obesogenic mechanism $(46,50)$ in this study. Last but not least, SCFA feeding was associated with a slightly lower weight gain, possibly making an additional contribution to the lower weight gain in HF mice.

That obesity and a leaky gut, as found in our mice receiving a LF-diet, can propagate bacterial translocation and drive autoimmunity is widely accepted $(35,38)$. Apart from a translocation of specific autoimmunity-triggering pathobionts into systemic organs $(13,51)$, the generally invoked metabolic endotoxemia can stimulate multiple immune cells via TLRs and lead to systemic low-grade inflammation (32). Such a scenario has recently been suggested in lupus-prone FcGRIIb ${ }^{-1-}$ mice treated with gut leakage-inducing dextran sodium sulfate (DSS) enhancing systemic inflammation, apoptosis and lupus progression (52). In addition and like endotoxemia, WAT itself is an important inducer of local and systemic low-grade inflammation as confirmed in our study. WAT not only serves as energy depot, but can also release a plethora of proinflammatory cytokines, such as TNF $\alpha$, IL-1 $\beta$ or IL-6 (53-55). In addition, adipocytes release 'adipokines' such as leptin, found to be elevated in our more obese LF-fed mice. Adipokines regulate effects such as satiety, energy expenditure and adipocyte metabolism $(56,57)$. Many of them also display proinflammatory properties and direct immune-regulatory effects. This not only contributes to the development of comorbidities (such as diabetes or cardiovascular disease), but could also worsen autoimmune pathogenesis $(35,58-61)$.

Diet shapes microbial communities in the gut influencing metabolic and immune responses (43-45). A fiber-mediated change in gut bacteria or SCFA composition was not specifically addressed here, but has been reported by a large number of previous publications $(6,23,25,62-66)$. Of course, this does not automatically imply that equivalent SCFA level changes and microbiota shifts prevail under the here employed conditions and using the NZB/W F1 strain. As colonic transit time not only regulates nutrient availability but also luminal wash out thereby shaping the microbiota ecosystem (67), microbiota- shifts appear probable also in our study and might propagate weight gain and/or affect the intestinal barrier function $(6,7,13$, 33). In contrast to that, fiber-associated changes of the intestinal barrier function are described to occur independently from cecal bacterial profiles (29) and could, for instance, be inflicted by a simple resorting of the gut microbiota to host-secreted mucus glycoproteins serving as a nutrient source during fiber deficiency (68). We found that low fiber intake reduced intestinal integrity along with the expression of molecules associated with mucus layer and epithelial repair. The lack of stringent effects of antibiotic treatment on lupus pathology in our study might argue against major microbiota-dependent effects in the given setting, it does however not exclude an involvement of the microbiome in disease-accelerating effects of the LF-diet. A limitation of this study is that this was not further addressed here. Feeding different diets with or without antibiotics and fecal transfer experiments might be required to solve this question. Additionally, such follow-up studies should consider and examine the impact of fiber-associated obesity as influencing variable on microbiota composition.

Likewise, feeding a SCFA mix did not significantly affect lupus pathology. In consideration of the frequently reported association between nutritional fiber contents and SCFA levels in feces and serum $(6,25)$, this is in accordance with our observation that a HF- compared to NF-diet only minimally ameliorated lupus progression. Thus, our results contrast with other studies $(13,69-71)$. While the cause underlying these differing outcomes of SCFA feeding and microbiota depletion on lupus pathology remains unclear, different factors might contribute. These include discrepancies in feeding regimes of specific fibers and SCFA, physicochemical characteristics of different fibers such as fermentability, solubility, and viscosity, animal facilities, as well as mouse strains and individual or strain-specific effects of the gut microbiota $(13,51,66,71-77)$. In support of the latter and mimicking the diversity in SLE patients, no simple overarching principle regarding the gutmicrobiota-lupus connection has been found in lupus-prone strains so far $(13,78,79)$.

Apart from strain- or feeding-specific circumstances and limitations, it needs to be considered that depending on the disease context, SCFA may even deteriorate disease pathology. It is becoming increasingly clear that the impact of SCFA on immune cells is not always merely anti-inflammatory (16). In CIA arthritis and experimental autoimmune encephalitis (EAE), early SCFA application could reduce disease severity, while increasing $\mathrm{K} / \mathrm{BxN}$ serum transfer arthritis (22). Apart from

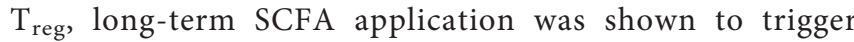
urethritis-inducing $\mathrm{T}_{\mathrm{H}} 1$ and $\mathrm{T}_{\mathrm{H}} 17$ cells when applied at higher than physiological levels (80). Such clearly pro-inflammatory effects were not noted in our studies, however it cannot be excluded they backfire anti-inflammatory actions leading to only minimal effects on the overall disease course. Furthermore, reported immunologic SCFA effects are not always consistent between studies, i.e. on $\mathrm{T}_{\text {reg }}$ frequencies and differentiation or on $\mathrm{T}_{\mathrm{FH}}$, plasma cell differentiation and Ig production $(7,14,15,22-$ 25, 69, 80-82). As SCFA effects may contextually vary, their 
influence in relation to different micro-environmental conditions and multicomponent disease states needs further exploration.

To sum up, in accordance with others, our murine study shows a clear association between reduced fiber intake and autoimmune pathology and a connection with systemically elevated cytokine levels, obesity, fat inflammation, gut leakage and immune-dysregulation $(6,7,12,13,32-38,83)$. The association between obesity and autoimmunity is generally recognized for different entities and may suggest a more general concept as well as synergism effects in the pathology of inflammatory, immune-mediated diseases.

In the human cohort, we could not explore the link between fiber intake and obesity reported in mice, but confirm an association between obesity, intestinal leakage and systemic inflammation, while adaptive immune activation was mainly associated with SLE disease activity. The lack of a clear correlation between obesity and immune activation does however not exclude, that in a setting of persistent antigen exposure, such as in chronic infections, autoimmune disease or cancer, systemically increased inflammatory cytokines, e.g. as a consequence of bacterial translocation or obesity, may additionally drive lymphocyte activation and disease progression. Such a scenario has been reported for HIV and also revealed a correlation with markers of cardiovascular comorbidity $(84,85)$. An increased risk of cardiovascular mortality related to a dysregulated innate and adaptive immune response was also reported in SLE (86).

Although not directly addressed here, we assume that the suspected multifactorial and synergistically acting factors may be bidirectionally linked, which is supported by previous reports. For instance, obesity is strongly associated with changes in the gut microbiome, gut leakage and bacterial translocation. Vice versa, WAT contributes to elevated levels of pro-inflammatory cytokines and adipokines, that-among other things-can induce apoptosis of enterocytes, disrupt tight junctions and contribute to gut dysbiosis and bacterial translocation $(11,33$, $34,36,37,63,87,88)$. The sharing of such common pathways is reflected in the clustering of comorbidities such as obesity, metabolic syndrome, diabetes or cardiovascular complications and the close connection with SLE/autoimmunity $(35,38,86,89$, 90). Therefore, it is important to understand their molecular links and how these are influenced by dietary factors. Given the high rise in inflammatory and autoimmune diseases and associated mortality, the translation of such findings in effective therapies and prevention strategies, might not only improve individual suffering, but also have an important socioeconomic impact.

\section{DATA AVAILABILITY STATEMENT}

The original contributions presented in the study are included in the article/Supplementary Material. Further inquiries can be directed to the corresponding author.

\section{ETHICS STATEMENT}

The studies involving human participants were reviewed and approved by Ethikkommission Universität Freiburg. The patients/participants provided their written informed consent to participate in this study. The animal study was reviewed and approved by Regierungspräsidium Freiburg.

\section{AUTHOR CONTRIBUTIONS}

NC designed research. NC, A-LS, AE, DS, AA, CD, CF, and ANK performed research. NC, A-LS, AE, CH, CD, SF, MR, ANK, CF, and $\mathrm{RV}$ analyzed data. US contributed new reagents/analytical tools. NC, A-LS, CD, MR, and RV contributed to manuscript editing. NC and A-LS wrote the paper. All authors contributed to the article and approved the submitted version.

\section{FUNDING}

This work was supported by the B. Braun-Foundation (Germany), Müller-Fahnenberg-Stiftung (Albert-LudwigUniversity of Freiburg, Germany), the Research Committee (Forschungskommission) of the Medical Faculty of the University of Freiburg, the Ministry of Science, Research, and Arts Baden-Wurttemberg (Margarete von Wrangell Programm to NC), Deutsche Forschungsgemeinschaft (DFG) (TRR 130, project 12 to RV) and Dr. Heinrich Kircher Foundation (AlbertLudwigs-University of Freiburg, Germany; to AE and AA).

\section{ACKNOWLEDGMENTS}

We thank all staff of the animal facility (CEMT) for help with animal care and husbandry, Rita Rzepka for organizational and infrastructural measures, Christine Reichenbach-Braun, Ana Venhoff, Renate Helfesrieder and Dr. Julia Dickow, Gaby Neumann and Dr. Florian Emmerich for technical support. We are very grateful to Dr. Kurt Lucas and Anna Lena Leifke (MPI Mainz) for their support using the LPS detection assay. We thank our research assistants Olga Greb, Kim Witetzec, JanaSusann Briem, and Jakov Korzhenevich for their support. We also thank Marei-Theresa Schleyer and Prof. Goran Marjanovic for help with patient recruitment. We thank Prof. Hans-Ulrich Endreß (Herbstreith \& Fox, Neuenbürg, Germany) for the kind provision of pectin.

\section{SUPPLEMENTARY MATERIAL}

The Supplementary Material for this article can be found online at: https://www.frontiersin.org/articles/10.3389/fimmu.2021. 696810/full\#supplementary-material 


\section{REFERENCES}

1. El-Gabalawy H, Guenther LC, Bernstein CN. Epidemiology of ImmuneMediated Inflammatory Diseases: Incidence, Prevalence, Natural History, and Comorbidities. J Rheumatol Suppl (2010) 85:2-10. doi: 10.3899/jrheum. 091461

2. Tsokos GC, Lo MS, Costa Reis P, Sullivan KE. New Insights Into the Immunopathogenesis of Systemic Lupus Erythematosus. Nat Rev Rheumatol (2016) 12(12):716-30. doi: 10.1038/nrrheum.2016.186

3. Rosenblum MD, Remedios KA, Abbas AK. Mechanisms of Human Autoimmunity. J Clin Invest (2015) 125(6):2228-33. doi: 10.1172/JCI78088

4. Thorburn AN, Macia L, Mackay CR. Diet, Metabolites, and "WesternLifestyle" Inflammatory Diseases. Immunity (2014) 40(6):833-42. doi: 10.1016/j.immuni.2014.05.014

5. Richards JL, Yap YA, McLeod KH, Mackay CR, Marino E. Dietary Metabolites and the Gut Microbiota: An Alternative Approach to Control Inflammatory and Autoimmune Diseases. Clin Transl Immunol (2016) 5(5): e82. doi: 10.1038/cti.2016.29

6. Macia L, Tan J, Vieira AT, Leach K, Stanley D, Luong S, et al. MetaboliteSensing Receptors GPR43 and GPR109A Facilitate Dietary Fibre-Induced Gut Homeostasis Through Regulation of the Inflammasome. Nat Commun (2015) 6:6734. doi: 10.1038/ncomms7734

7. Tan J, McKenzie C, Vuillermin PJ, Goverse G, Vinuesa CG, Mebius RE, et al. Dietary Fiber and Bacterial SCFA Enhance Oral Tolerance and Protect Against Food Allergy Through Diverse Cellular Pathways. Cell Rep (2016) 15(12):2809-24. doi: 10.1016/j.celrep.2016.05.047

8. Martinez I, Stegen JC, Maldonado-Gomez MX, Eren AM, Siba PM, Greenhill AR, et al. The Gut Microbiota of Rural Papua New Guineans: Composition, Diversity Patterns, and Ecological Processes. Cell Rep (2015) 11(4):527-38. doi: 10.1016/j.celrep.2015.03.049

9. De Filippo C, Cavalieri D, Di Paola M, Ramazzotti M, Poullet JB, Massart S, et al. Impact of Diet in Shaping Gut Microbiota Revealed by a Comparative Study in Children From Europe and Rural Africa. Proc Natl Acad Sci USA (2010) 107(33):14691-6. doi: 10.1073/pnas.1005963107

10. Schnorr SL, Candela M, Rampelli S, Centanni M, Consolandi C, Basaglia G, et al. Gut Microbiome of the Hadza Hunter-Gatherers. Nat Commun (2014) 5:3654. doi: $10.1038 /$ ncomms4654

11. Koliada A, Syzenko G, Moseiko V, Budovska L, Puchkov K, Perederiy V, et al. Association Between Body Mass Index and Firmicutes/Bacteroidetes Ratio in an Adult Ukrainian Population. BMC Microbiol (2017) 17(1):120. doi: 10.1186/s12866-017-1027-1

12. Willemsen LE, Koetsier MA, van Deventer SJ, van Tol EA. Short Chain Fatty Acids Stimulate Epithelial Mucin 2 Expression Through Differential Effects on Prostaglandin E(1) and E(2) Production by Intestinal Myofibroblasts. Gut (2003) 52(10):1442-7. doi: 10.1136/gut.52.10.1442

13. Zegarra-Ruiz DF, El Beidaq A, Iniguez AJ, Lubrano Di Ricco M, Manfredo Vieira S, Ruff WE, et al. A Diet-Sensitive Commensal Lactobacillus Strain Mediates TLR7-Dependent Systemic Autoimmunity. Cell Host Microbe (2019) 25(1):113-27.e6. doi: 10.1016/j.chom.2018.11.009

14. Arpaia N, Campbell C, Fan X, Dikiy S, van der Veeken J, deRoos P, et al. Metabolites Produced by Commensal Bacteria Promote Peripheral Regulatory T-Cell Generation. Nature (2013) 504(7480):451-5. doi: 10.1038 /nature12726

15. Furusawa Y, Obata Y, Fukuda S, Endo TA, Nakato G, Takahashi D, et al. Commensal Microbe-Derived Butyrate Induces the Differentiation of Colonic Regulatory T Cells. Nature (2013) 504(7480):446-50. doi: 10.1038/ nature 12721

16. Correa-Oliveira R, Fachi JL, Vieira A, Sato FT, Vinolo MA. Regulation of Immune Cell Function by Short-Chain Fatty Acids. Clin Transl Immunol (2016) 5(4):e73. doi: 10.1038/cti.2016.17

17. Lin HV, Frassetto A, Kowalik EJ Jr, Nawrocki AR, Lu MM, Kosinski JR, et al. Butyrate and Propionate Protect Against Diet-Induced Obesity and Regulate Gut Hormones via Free Fatty Acid Receptor 3-Independent Mechanisms. PloS One (2012) 7(4):e35240. doi: 10.1371/journal.pone.0035240

18. Adam CL, Thomson LM, Williams PA, Ross AW. Soluble Fermentable Dietary Fibre (Pectin) Decreases Caloric Intake, Adiposity and Lipidaemia in High-Fat Diet-Induced Obese Rats. PloS One (2015) 10(10):e0140392. doi: 10.1371/journal.pone.0140392
19. Kimura I, Inoue D, Maeda T, Hara T, Ichimura A, Miyauchi S, et al. ShortChain Fatty Acids and Ketones Directly Regulate Sympathetic Nervous System via G Protein-Coupled Receptor 41 (GPR41). Proc Natl Acad Sci USA (2011) 108(19):8030-5. doi: 10.1073/pnas.1016088108

20. Lucas S, Omata Y, Hofmann J, Bottcher M, Iljazovic A, Sarter K, et al. ShortChain Fatty Acids Regulate Systemic Bone Mass and Protect From Pathological Bone Loss. Nat Commun (2018) 9(1):55. doi: 10.1038/s41467017-02490-4

21. Azizov V, Dietel K, Steffen F, Durholz K, Meidenbauer J, Lucas S, et al. Ethanol Consumption Inhibits TFH Cell Responses and the Development of Autoimmune Arthritis. Nat Commun (2020) 11(1):1998. doi: 10.1038/s41467020-15855-z

22. Mizuno M, Noto D, Kaga N, Chiba A, Miyake S. The Dual Role of Short Fatty Acid Chains in the Pathogenesis of Autoimmune Disease Models. PloS One (2017) 12(2):e0173032. doi: 10.1371/journal.pone.0173032

23. Thorburn AN, McKenzie CI, Shen S, Stanley D, Macia L, Mason LJ, et al. Evidence That Asthma Is a Developmental Origin Disease Influenced by Maternal Diet and Bacterial Metabolites. Nat Commun (2015) 6:7320. doi: $10.1038 /$ ncomms 8320

24. Marino E, Richards JL, McLeod KH, Stanley D, Yap YA, Knight J, et al. Gut Microbial Metabolites Limit the Frequency of Autoimmune T Cells and Protect Against Type 1 Diabetes. Nat Immunol (2017) 18(5):552-62. doi: 10.1038/ni.3713

25. Trompette A, Gollwitzer ES, Yadava K, Sichelstiel AK, Sprenger N, Ngom-Bru C, et al. Gut Microbiota Metabolism of Dietary Fiber Influences Allergic Airway Disease and Hematopoiesis. Nat Med (2014) 20(2):159-66. doi: 10.1038/nm.3444

26. Fossati-Jimack L, Ioan-Facsinay A, Reininger L, Chicheportiche Y, Watanabe N, Saito T, et al. Markedly Different Pathogenicity of Four Immunoglobulin G Isotype-Switch Variants of an Antierythrocyte Autoantibody Is Based on Their Capacity to Interact In Vivo With the Low-Affinity Fcgamma Receptor III. J Exp Med (2000) 191(8):1293-302. doi: 10.1084/jem.191.8.1293

27. Humrich JY, Morbach H, Undeutsch R, Enghard P, Rosenberger S, Weigert O, et al. Homeostatic Imbalance of Regulatory and Effector T Cells Due to IL-2 Deprivation Amplifies Murine Lupus. Proc Natl Acad Sci USA (2010) 107 (1):204-9. doi: 10.1073/pnas.0903158107

28. Tedeschi SK, Barbhaiya M, Malspeis S, Lu B, Sparks JA, Karlson EW, et al. Obesity and the Risk of Systemic Lupus Erythematosus Among Women in the Nurses' Health Studies. Semin Arthritis Rheum (2017) 47(3):376-83. doi: 10.1016/j.semarthrit.2017.05.011

29. Drew JE, Reichardt N, Williams LM, Mayer CD, Walker AW, Farquharson AJ, et al. Dietary Fibers Inhibit Obesity in Mice, But Host Responses in the Cecum and Liver Appear Unrelated to Fiber-Specific Changes in Cecal Bacterial Taxonomic Composition. Sci Rep (2018) 8(1):15566. doi: 10.1038/ s41598-018-34081-8

30. Muller M, Canfora EE, Blaak EE. Gastrointestinal Transit Time, Glucose Homeostasis and Metabolic Health: Modulation by Dietary Fibers. Nutrients (2018) 10(3):149-73. doi: 10.3390/nu10030275

31. Pelaseyed T, Bergstrom JH, Gustafsson JK, Ermund A, Birchenough GM, Schutte A, et al. The Mucus and Mucins of the Goblet Cells and Enterocytes Provide the First Defense Line of the Gastrointestinal Tract and Interact With the Immune System. Immunol Rev (2014) 260(1):8-20. doi: 10.1111/ imr.12182

32. Brenchley JM, Douek DC. Microbial Translocation Across the GI Tract. Annu Rev Immunol (2012) 30:149-73. doi: 10.1146/annurev-immunol-020711075001

33. Cani PD, Amar J, Iglesias MA, Poggi M, Knauf C, Bastelica D, et al. Metabolic Endotoxemia Initiates Obesity and Insulin Resistance. Diabetes (2007) 56 (7):1761-72. doi: 10.2337/db06-1491

34. Cani PD, Osto M, Geurts L, Everard A. Involvement of Gut Microbiota in the Development of Low-Grade Inflammation and Type 2 Diabetes Associated With Obesity. Gut Microbes (2012) 3(4):279-88. doi: 10.4161/gmic.19625

35. Gremese E, Tolusso B, Gigante MR, Ferraccioli G. Obesity as a Risk and Severity Factor in Rheumatic Diseases (Autoimmune Chronic Inflammatory Diseases). Front Immunol (2014) 5:576. doi: 10.3389/fimmu.2014.00576

36. Gummesson A, Carlsson LM, Storlien LH, Backhed F, Lundin P, Lofgren L, et al. Intestinal Permeability Is Associated With Visceral Adiposity in Healthy Women. Obes (Silver Spring) (2011) 19(11):2280-2. doi: 10.1038/oby.2011.251 
37. Monteiro R, Azevedo I. Chronic Inflammation in Obesity and the Metabolic Syndrome. Mediators Inflamm (2010) 2010:1-10. doi: 10.1155/2010/289645

38. Versini M, Aljadeff G, Jeandel PY, Shoenfeld Y. Obesity: An Additional Piece in the Mosaic of Autoimmunity. Isr Med Assoc J (2014) 16(10):619-21. doi: 10.1016/j.autrev.2014.07.001

39. Bindels LB, Segura Munoz RR, Gomes-Neto JC, Mutemberezi V, Martinez I, Salazar N, et al. Resistant Starch can Improve Insulin Sensitivity Independently of the Gut Microbiota. Microbiome (2017) 5(1):12. doi: 10.1186/s40168-017-0230-5

40. Zou J, Chassaing B, Singh V, Pellizzon M, Ricci M, Fythe MD, et al. FiberMediated Nourishment of Gut Microbiota Protects Against Diet-Induced Obesity by Restoring IL-22-Mediated Colonic Health. Cell Host Microbe (2018) 23(1):41-53.e4. doi: 10.1016/j.chom.2017.11.003

41. Soliman GA. Dietary Fiber, Atherosclerosis, and Cardiovascular Disease. Nutrients (2019) 11(5):1-11. doi: 10.3390/nu1 1051155

42. Chen JP, Chen GC, Wang XP, Qin L, Bai Y. Dietary Fiber and Metabolic Syndrome: A Meta-Analysis and Review of Related Mechanisms. Nutrients (2017) 10(1):1-17. doi: 10.3390/nu10010024

43. Carmody RN, Gerber GK, Luevano JMJr., Gatti DM, Somes L, Svenson KL, et al. Diet Dominates Host Genotype in Shaping the Murine Gut Microbiota. Cell Host Microbe (2015) 17(1):72-84. doi: 10.1016/j.chom.2014.11.010

44. Hooper LV, Littman DR, Macpherson AJ. Interactions Between the Microbiota and the Immune System. Science (2012) 336(6086):1268-73. doi: $10.1126 /$ science. 1223490

45. Kau AL, Ahern PP, Griffin NW, Goodman AL, Gordon JI. Human Nutrition, the Gut Microbiome and the Immune System. Nature (2011) 474(7351):32736. doi: $10.1038 /$ nature 10213

46. Clark MJ, Slavin JL. The Effect of Fiber on Satiety and Food Intake: A Systematic Review. J Am Coll Nutr (2013) 32(3):200-11. doi: 10.1080/ 07315724.2013.791194

47. Eastwood MA, Morris ER. Physical Properties of Dietary Fiber That Influence Physiological Function: A Model for Polymers Along the Gastrointestinal Tract. Am J Clin Nutr (1992) 55(2):436-42. doi: 10.1093/ajcn/55.2.436

48. Howarth NC, Saltzman E, Roberts SB. Dietary Fiber and Weight Regulation. Nutr Rev (2001) 59(5):129-39. doi: 10.1111/j.1753-4887.2001.tb07001.x

49. Jenkins DJ, Wolever TM, Leeds AR, Gassull MA, Haisman P, Dilawari J, et al. Dietary Fibres, Fibre Analogues, and Glucose Tolerance: Importance of Viscosity. Br Med J (1978) 1(6124):1392-4. doi: 10.1136/bmj.1.6124.1392

50. Ye Z, Arumugam V, Haugabrooks E, Williamson P, Hendrich S. Soluble Dietary Fiber (Fibersol-2) Decreased Hunger and Increased Satiety Hormones in Humans When Ingested With a Meal. Nutr Res (2015) 35(5):393-400. doi: 10.1016/j.nutres.2015.03.004

51. Manfredo Vieira S, Hiltensperger M, Kumar V, Zegarra-Ruiz D, Dehner C, Khan N, et al. Translocation of a Gut Pathobiont Drives Autoimmunity in Mice and Humans. Science (2018) 359(6380):1156-61. doi: 10.1126/ science.aar7201

52. Thim-Uam A, Surawut $S$, Issara-Amphorn J, Jaroonwitchawan $T$, Hiengrach P, Chatthanathon P, et al. Leaky-Gut Enhanced Lupus Progression in the Fc Gamma Receptor-IIb Deficient and Pristane-Induced Mouse Models of Lupus. Sci Rep (2020) 10(1):777. doi: 10.1038/s41598-019-57275-0

53. Yu JY, Choi WJ, Lee HS, Lee JW. Relationship Between Inflammatory Markers and Visceral Obesity in Obese and Overweight Korean Adults: An Observational Study. Med (Baltimore) (2019) 98(9):e14740. doi: 10.1097/ MD. 0000000000014740

54. Bullo M, Garcia-Lorda P, Megias I, Salas-Salvado J. Systemic Inflammation, Adipose Tissue Tumor Necrosis Factor, and Leptin Expression. Obes Res (2003) 11(4):525-31. doi: 10.1038/oby.2003.74

55. Anto Michel N, Colberg C, Buscher K, Sommer B, Pramod AB, Ehinger E, et al. Inflammatory Pathways Regulated by Tumor Necrosis Receptor-Associated Factor 1 Protect From Metabolic Consequences in Diet-Induced Obesity. Circ Res (2018) 122(5):693-700. doi: 10.1161/CIRCRESAHA.117.312055

56. Perez C, Fernandez-Galaz C, Fernandez-Agullo T, Arribas C, Andres A, Ros M, et al. Leptin Impairs Insulin Signaling in Rat Adipocytes. Diabetes (2004) 53(2):347-53. doi: 10.2337/diabetes.53.2.347

57. Rezai-Zadeh K, Yu S, Jiang Y, Laque A, Schwartzenburg C, Morrison CD, et al. Leptin Receptor Neurons in the Dorsomedial Hypothalamus Are Key Regulators of Energy Expenditure and Body Weight, But Not Food Intake. Mol Metab (2014) 3(7):681-93. doi: 10.1016/j.molmet.2014.07.008
58. Frommer KW, Zimmermann B, Meier FM, Schroder D, Heil M, Schaffler A, et al. Adiponectin-Mediated Changes in Effector Cells Involved in the Pathophysiology of Rheumatoid Arthritis. Arthritis Rheum (2010) 62 (10):2886-99. doi: 10.1002/art.27616

59. Huh JY, Park YJ, Ham M, Kim JB. Crosstalk Between Adipocytes and Immune Cells in Adipose Tissue Inflammation and Metabolic Dysregulation in Obesity. Mol Cells (2014) 37(5):365-71. doi: 10.14348/ molcells.2014.0074

60. Lourenco EV, Liu A, Matarese G, La Cava A. Leptin Promotes Systemic Lupus Erythematosus by Increasing Autoantibody Production and Inhibiting Immune Regulation. Proc Natl Acad Sci USA (2016) 113(38):10637-42. doi: 10.1073/pnas.1607101113

61. Yu Y, Liu Y, Shi FD, Zou H, Matarese G, La Cava A. Cutting Edge: LeptinInduced RORgammat Expression in CD4+ T Cells Promotes Th17 Responses in Systemic Lupus Erythematosus. J Immunol (2013) 190(7):3054-8. doi: 10.4049/jimmunol.1203275

62. Chung WS, Walker AW, Louis P, Parkhill J, Vermeiren J, Bosscher D, et al. Modulation of the Human Gut Microbiota by Dietary Fibres Occurs at the Species Level. BMC Biol (2016) 14:3. doi: 10.1186/s12915-015-0224-3

63. Ellekilde M, Selfjord E, Larsen CS, Jakesevic M, Rune I, Tranberg B, et al. Transfer of Gut Microbiota From Lean and Obese Mice to Antibiotic-Treated Mice. Sci Rep (2014) 4:5922. doi: 10.1038/srep05922

64. Geurts L, Lazarevic V, Derrien M, Everard A, Van Roye M, Knauf C, et al. Altered Gut Microbiota and Endocannabinoid System Tone in Obese and Diabetic Leptin-Resistant Mice: Impact on Apelin Regulation in Adipose Tissue. Front Microbiol (2011) 2:149. doi: 10.3389/fmicb.2011.00149

65. Tremaroli V, Backhed F. Functional Interactions Between the Gut Microbiota and Host Metabolism. Nature (2012) 489(7415):242-9. doi: 10.1038/nature11552

66. Walker AW, Ince J, Duncan SH, Webster LM, Holtrop G, Ze X, et al. Dominant and Diet-Responsive Groups of Bacteria Within the Human Colonic Microbiota. ISME J (2011) 5(2):220-30. doi: 10.1038/ ismej. 2010.118

67. Cremer J, Segota I, Yang CY, Arnoldini M, Sauls JT, Zhang Z, et al. Effect of Flow and Peristaltic Mixing on Bacterial Growth in a Gut-Like Channel. Proc Natl Acad Sci U.S.A. (2016) 113(41):11414-9. doi: 10.1073/pnas.1601306113

68. Desai MS, Seekatz AM, Koropatkin NM, Kamada N, Hickey CA, Wolter M, et al. A Dietary Fiber-Deprived Gut Microbiota Degrades the Colonic Mucus Barrier and Enhances Pathogen Susceptibility. Cell (2016) 167(5):133953.e21. doi: 10.1016/j.cell.2016.10.043

69. Sanchez HN, Moroney JB, Gan H, Shen T, Im JL, Li T, et al. B Cell-Intrinsic Epigenetic Modulation of Antibody Responses by Dietary Fiber-Derived Short-Chain Fatty Acids. Nat Commun (2020) 11(1):60. doi: 10.1038/ s41467-019-13603-6

70. Mu Q, Tavella VJ, Kirby JL, Cecere TE, Chung M, Lee J, et al. Antibiotics Ameliorate Lupus-Like Symptoms in Mice. Sci Rep (2017) 7(1):13675. doi: 10.1038/s41598-017-14223-0

71. Mu Q, Zhang H, Liao X, Lin K, Liu H, Edwards MR, et al. Control of Lupus Nephritis by Changes of Gut Microbiota. Microbiome (2017) 5(1):73. doi: 10.1186/s40168-017-0300-8

72. Hernandez MAG, Canfora EE, Jocken JWE, Blaak EE. The Short-Chain Fatty Acid Acetate in Body Weight Control and Insulin Sensitivity. Nutrients (2019) 11(8):1-32. doi: 10.3390/nu11081943

73. Holscher HD. Dietary Fiber and Prebiotics and the Gastrointestinal Microbiota. Gut Microbes (2017) 8(2):172-84. doi: 10.1080/19490976.2017.1290756

74. Goodrich JK, Waters JL, Poole AC, Sutter JL, Koren O, Blekhman R, et al. Human Genetics Shape the Gut Microbiome. Cell (2014) 159(4):789-99. doi: 10.1016/j.cell.2014.09.053

75. Dehner C, Fine R, Kriegel MA. The Microbiome in Systemic Autoimmune Disease: Mechanistic Insights From Recent Studies. Curr Opin Rheumatol (2019) 31(2):201-7. doi: 10.1097/BOR.0000000000000574

76. Luo XM, Edwards MR, Mu Q, Yu Y, Vieson MD, Reilly CM, et al. Gut Microbiota in Human Systemic Lupus Erythematosus and a Mouse Model of Lupus. Appl Environ Microbiol (2018) 84(4):1-10. doi: 10.1128/ AEM.02288-17

77. Manirarora JN, Kosiewicz MM, Alard P. Feeding Lactobacilli Impacts Lupus Progression in (NZBxNZW)F1 Lupus-Prone Mice by Enhancing Immunoregulation. Autoimmunity (2020) 53:1-10. doi: 10.1080/08916934. 2020.1777282 
78. Maldonado MA, Kakkanaiah V, MacDonald GC, Chen F, Reap EA, Balish E, et al. The Role of Environmental Antigens in the Spontaneous Development of Autoimmunity in MRL-Lpr Mice. J Immunol (1999) 162 (11):6322-30.

79. Choi SC, Brown J, Gong M, Ge Y, Zadeh M, Li W, et al. Gut Microbiota Dysbiosis and Altered Tryptophan Catabolism Contribute to Autoimmunity in Lupus-Susceptible Mice. Sci Transl Med (2020) 12(551):1-33. doi: 10.1126/ scitranslmed.aax 2220

80. Park J, Goergen CJ, HogenEsch H, Kim CH. Chronically Elevated Levels of Short-Chain Fatty Acids Induce T Cell-Mediated Ureteritis and Hydronephrosis. J Immunol (2016) 196(5):2388-400. doi: 10.4049/ jimmunol.1502046

81. Haghikia A, Jorg S, Duscha A, Berg J, Manzel A, Waschbisch A, et al. Dietary Fatty Acids Directly Impact Central Nervous System Autoimmunity via the Small Intestine. Immunity (2015) 43(4):817-29. doi: 10.1016/j.immuni. 2015.09.007

82. Kim M, Qie Y, Park J, Kim CH. Gut Microbial Metabolites Fuel Host Antibody Responses. Cell Host Microbe (2016) 20(2):202-14. doi: 10.1016/ j.chom.2016.07.001

83. Jangra S, RS K, Sharma RK, Pothuraju R, Mohanty AK. Ameliorative Effect of Fermentable Fibres on Adiposity and Insulin Resistance in C57BL/6 Mice Fed a High-Fat and Sucrose Diet. Food Funct (2019) 10(6):3696-705. doi: 10.1039/ C8FO02578A

84. Shan L, Siliciano RF. Unraveling the Relationship Between Microbial Translocation and Systemic Immune Activation in HIV Infection. J Clin Invest (2014) 124(6):2368-71. doi: 10.1172/JCI75799

85. Kristoff J, Haret-Richter G, Ma D, Ribeiro RM, Xu C, Cornell E, et al. Early Microbial Translocation Blockade Reduces SIV-Mediated Inflammation and Viral Replication. J Clin Invest (2014) 124(6):2802-6. doi: 10.1172/JCI75090
86. Nagy G, Nemeth N, Buzas EI. Mechanisms of Vascular Comorbidity in Autoimmune Diseases. Curr Opin Rheumatol (2018) 30(2):197-206. doi: 10.1097/BOR.0000000000000483

87. Galmes S, Cifre M, Palou A, Oliver P, Serra F. A Genetic Score of Predisposition to Low-Grade Inflammation Associated With Obesity May Contribute to Discern Population at Risk for Metabolic Syndrome. Nutrients (2019) 11(2):1-19. doi: 10.3390/nu11020298

88. Epple HJ, Allers K, Troger H, Kuhl A, Erben U, Fromm M, et al. Acute HIV Infection Induces Mucosal Infiltration With CD4+ and CD8+ T Cells, Epithelial Apoptosis, and a Mucosal Barrier Defect. Gastroenterology (2010) 139(4):1289-300. doi: 10.1053/j.gastro.2010.06.065

89. Swinburn BA, Sacks G, Hall KD, McPherson K, Finegood DT, Moodie ML, et al. The Global Obesity Pandemic: Shaped by Global Drivers and Local Environments. Lancet (2011) 378(9793):804-14. doi: 10.1016/S0140-6736(11) 60813-1

90. Versini M, Jeandel PY, Rosenthal E, Shoenfeld Y. Obesity in Autoimmune Diseases: Not a Passive Bystander. Autoimmun Rev (2014) 13(9):981-1000. doi: 10.1016/j.autrev.2014.07.001

Conflict of Interest: The authors declare that the research was conducted in the absence of any commercial or financial relationships that could be construed as a potential conflict of interest.

Copyright (c) 2021 Schäfer, Eichhorst, Hentze, Kraemer, Amend, Sprenger, Fluhr, Finzel, Daniel, Salzer, Rizzi, Voll and Chevalier. This is an open-access article distributed under the terms of the Creative Commons Attribution License (CC BY). The use, distribution or reproduction in other forums is permitted, provided the original author(s) and the copyright owner(s) are credited and that the original publication in this journal is cited, in accordance with accepted academic practice. No use, distribution or reproduction is permitted which does not comply with these terms. 